University of Tennessee Health Science Center UTHSC Digital Commons

\title{
$5-2019$
}

\section{Transcriptional Regulation of NLRC4 Inflammasome by IRF8}

\author{
Ein Lee \\ University of Tennessee Health Science Center
}

Follow this and additional works at: https://dc.uthsc.edu/dissertations

Part of the Medical Immunology Commons, Medical Microbiology Commons, and the Medical Molecular Biology Commons

\section{Recommended Citation}

Lee, Ein (http://orcid.org/0000-0002-9363-5317), "Transcriptional Regulation of NLRC4 Inflammasome by IRF8" (2019). Theses and Dissertations (ETD). Paper 465. http://dx.doi.org/10.21007/ etd.cghs.2019.0458.

This Thesis is brought to you for free and open access by the College of Graduate Health Sciences at UTHSC Digital Commons. It has been accepted for inclusion in Theses and Dissertations (ETD) by an authorized administrator of UTHSC Digital Commons. For more information, please contact jwelch30@uthsc.edu. 


\title{
Transcriptional Regulation of NLRC4 Inflammasome by IRF8
}

\author{
Abstract \\ The NLRC4 inflammasome is a crucial part of the innate immune response against bacterial infections. \\ We found that NLRC4 inflammasome activation in bone marrow-derived macrophages (BMDMs) is \\ greatly dependent on interferon regulatory factor 8 (IRF8). NLRC4-mediated caspase-1 activation and \\ subsequent production of the inflammasome-dependent cytokines IL-1 $\beta$ and IL-18 and cell death were \\ impaired in IRF8-deficient cells. IRF8 mediated the transcription of genes encoding NAIPs, the receptors \\ for NLRC4 inflammasome, which recognize bacterial flagellin and type III secretion system (T3SS) \\ proteins. IRF8 was critical for host survival following infection with Salmonella Typhimurium or \\ Burkholderia thailandensis. Furthermore, mice deficient in IRF8 were impaired in their ability to produce \\ IL-18 and suffered higher bacterial burdens. Altogether, our data highlights the role of IRF8 as a \\ transcriptional regulator of NAIPs for NLRC4 inflammasome activation. \\ Document Type \\ Thesis \\ Degree Name \\ Master of Science (MS) \\ Program \\ Biomedical Sciences \\ Research Advisor \\ Thirumala-Devi Kanneganti, Ph.D. \\ Keywords \\ Inflammasome, Interferon regulatory factor, IRF8, NAIP, NLRC4, Salmonella \\ Subject Categories \\ Medical Immunology | Medical Microbiology | Medical Molecular Biology | Medical Sciences | Medicine \\ and Health Sciences
}


Transcriptional Regulation of NLRC4 Inflammasome by IRF8

\author{
A Thesis \\ Presented for \\ The Graduate Studies Council \\ The University of Tennessee \\ Health Science Center \\ In Partial Fulfillment \\ Of the Requirements for the Degree \\ Master of Science \\ From The University of Tennessee
}

By

Ein Lee

May 2019 
Chapters 2 and 3 and Portions of Chapter 4 (C) 2018 by Elsevier.

All other material (C 2019 by Ein Lee.

All rights reserved. 


\section{ACKNOWLEDGEMENTS}

The work for this thesis would not have been possible without the guidance and support of my mentor Thirumala-Devi Kanneganti of St. Jude Children's Research Hospital. I am grateful to my Committee members Elizabeth A. Fitzpatrick and David R. Nelson for their warm encouragement. I thank past and present members of the Kanneganti Lab. I was fortunate enough to work with colleagues who made science more enjoyable. Special thanks to Rajendra Karki, David Place, Parimal Samir, Jayadev Mavuluri, Bhesh Sharma, Arjun Balakrishnan, Subbarao Malireddi, Rechel Geiger, and Qifan Zhu for their contributions to this thesis. I thank Geoffrey Neale from the Genomics Department of St. Jude Children's Research Hospital for help with microarray data. This research was funded by US National Institutes of Health (AI101935, AI124346, AR056296 and CA163507), and the American Lebanese Syrian Associated Charities.

Finally, I want to express my gratitude to friends and family for being the amazing people they are. 


\begin{abstract}
The NLRC4 inflammasome is a crucial part of the innate immune response against bacterial infections. We found that NLRC4 inflammasome activation in bone marrow-derived macrophages (BMDMs) is greatly dependent on interferon regulatory factor 8 (IRF8). NLRC4-mediated caspase-1 activation and subsequent production of the inflammasome-dependent cytokines IL-1 $\beta$ and IL-18 and cell death were impaired in IRF8-deficient cells. IRF8 mediated the transcription of genes encoding NAIPs, the receptors for NLRC4 inflammasome, which recognize bacterial flagellin and type III secretion system (T3SS) proteins. IRF8 was critical for host survival following infection with Salmonella Typhimurium or Burkholderia thailandensis. Furthermore, mice deficient in IRF8 were impaired in their ability to produce IL-18 and suffered higher bacterial burdens. Altogether, our data highlights the role of IRF8 as a transcriptional regulator of NAIPs for NLRC4 inflammasome activation.
\end{abstract}




\section{TABLE OF CONTENTS}

CHAPTER 1. INTRODUCTION .....................................................................................

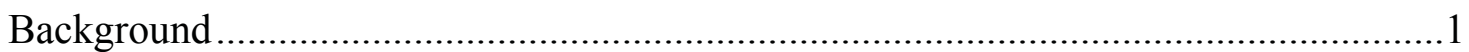

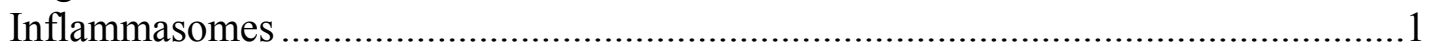

Interferon Signaling in Inflammasome Activation ................................................

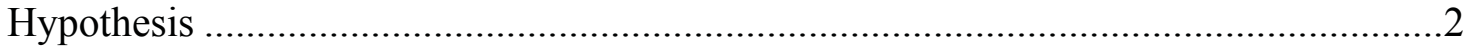

CHAPTER 2. MATERIALS AND METHODS..........................................................4

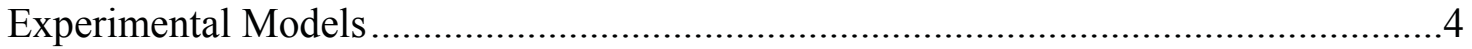

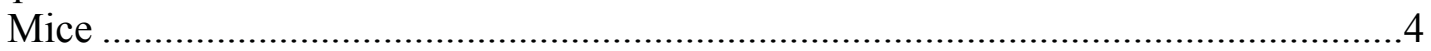

Bone Marrow-Derived Macrophages (BMDMs) ..................................................4

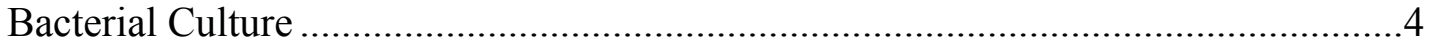

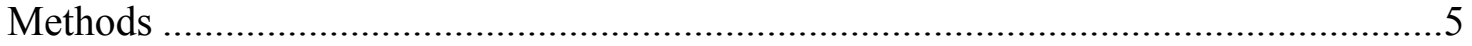

Stimulation of BMDMs ..........................................................................

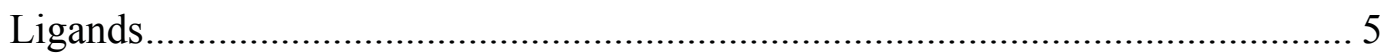

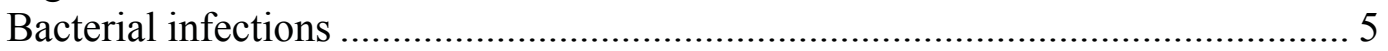

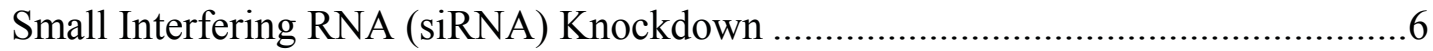

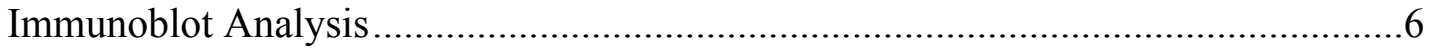

Real-Time PCR (RT-PCR) Analysis ................................................................6

Cytokine Analysis ............................................................................................

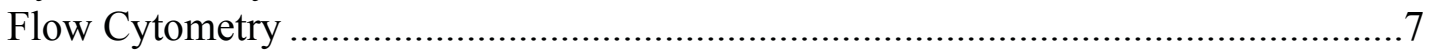

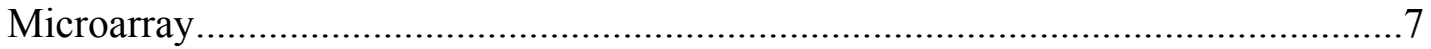

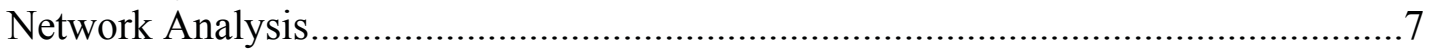

Chromatin Immunoprecipitation-Sequencing (ChIP-Seq) ...................................

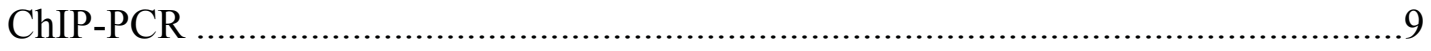

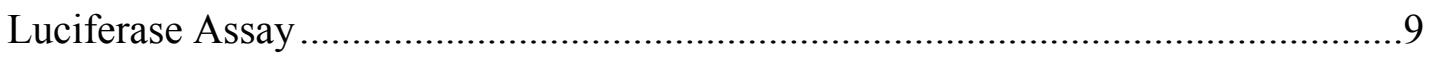

Electrophoretic Mobility Shift Assay (EMSA) ..................................................

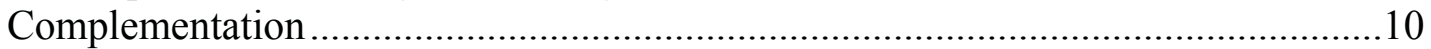

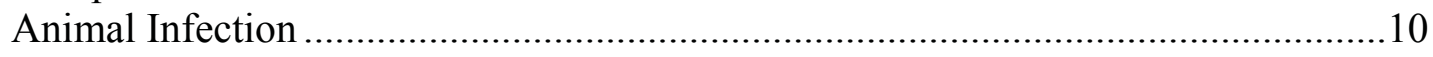

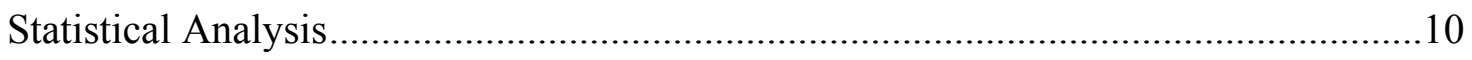

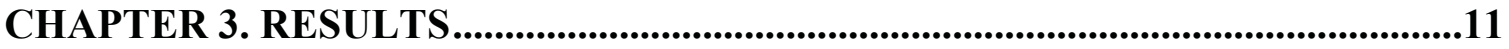

IRF8 Is Dispensable for AIM2, NLRP3, and Pyrin Inflammasome Activation............11

IRF8 Is Required for Optimal NLRC4 Inflammasome Activation ............................17

Salmonella Typhimurium-Dependent NLRC4 Inflammasome Activation ...............17

$P$. aeruginosa and $B$. thailandensis-Dependent NLRC4 Inflammasome

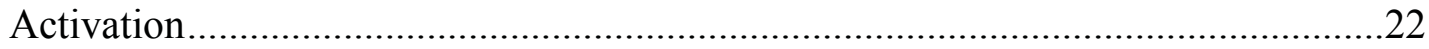

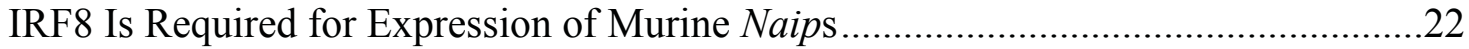

Differential Expression of NLRC4 Inflammasome Components .............................22

Transcriptional Regulation of NLRC4 Inflammasome.......................................25

Functional Regulation of Individual NAIPs .....................................................29

IRF8 Protects Against $S$. Typhimurium and B. thailandensis Infection In Vivo ...........33

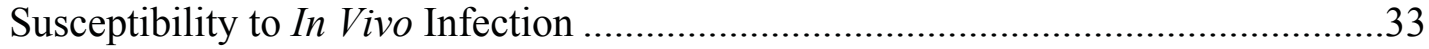

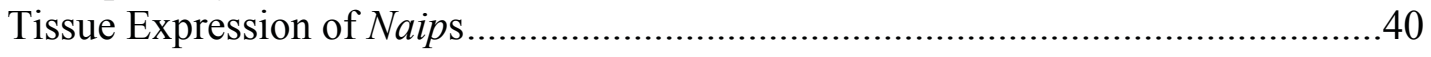




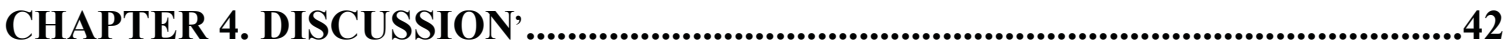

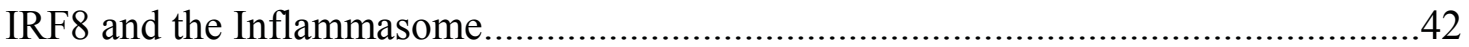

Additional Factors That May Regulate NLRC4 Inflammasome ...............................43

Physiological Relevance of Differential Expression of Naips..................................43

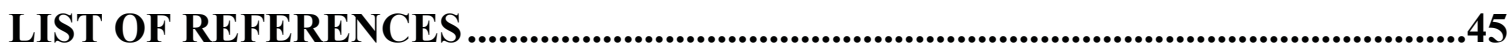

VITA 


\section{LIST OF TABLES}

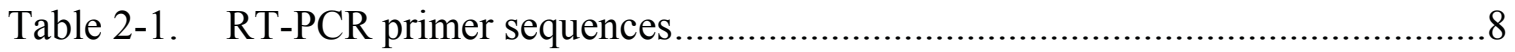

Table 2-2. ChIP-PCR primer sequences............................................................10 


\section{LIST OF FIGURES}

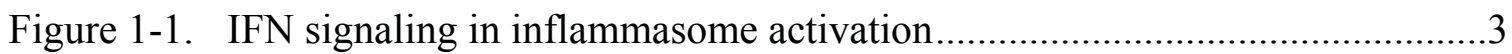

Figure 3-1. IRF8 does not affect the activation of AIM2, NLRP3, or Pyrin

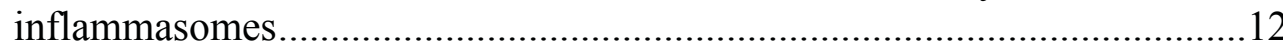

Figure 3-2. Inflammasome-independent cytokine secretion and cell death in response to various stimuli are not altered by IRF8

Figure 3-3. IRF8 is necessary for NLRC4 inflammasome activation in various doses

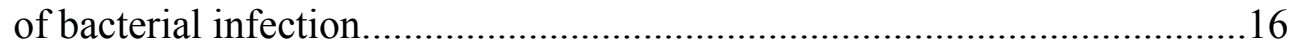

Figure 3-4. IRF8 is necessary for NLRC4 inflammasome activation induced by

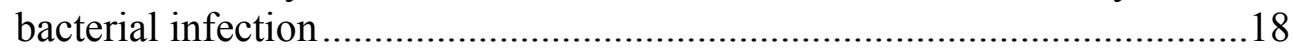

Figure 3-5. IRF8 is required for NLRC4 inflammasome activity but not for inflammasome-independent cytokine release after various bacterial infections 20

Figure 3-6. Absence of IRF8 attenuates NLRC4 activation.............................................23

Figure 3-7. IRF8 is a key factor in transcriptional regulation of Naips..........................26

Figure 3-8. Gene expression of Naips is unaltered in BMDMs deficient in IFN

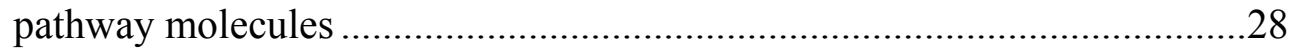

Figure 3-9. Transcriptional activity of IRF8 for Naips...................................................30

Figure 3-10. NLRC4 inflammasome activation in response to isolated bacterial proteins is impaired in the absence of IRF8 ................................................31

Figure 3-11. IRF8 confers protection against $S$. Typhimurium in vivo ……......................34

Figure 3-12. IRF8 confers protection against $B$. thailandensis in vivo ...............................36

Figure 3-13. IRF8-deficient mice have sufficient numbers of circulatory immune cells

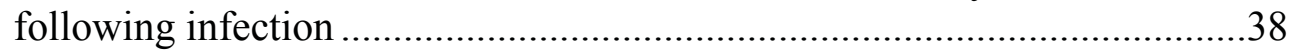

Figure 3-14. Inflammasome-dependent cytokines and pyroptosis both contribute to protection against $S$. Typhimurium infection in vivo 


\section{LIST OF ABBREVIATIONS}

\begin{tabular}{|c|c|}
\hline AIM2 & Absent in melanoma-2 \\
\hline BIR & Baculovirus inhibitor of apoptosis protein repeat \\
\hline BMDM & Bone marrow-derived macrophage \\
\hline CARD & Caspase activation and recruitment domain \\
\hline $\mathrm{CFU}$ & Colony forming units \\
\hline ChIP-seq & Chromatin immunoprecipitation-sequencing \\
\hline DAMP & Danger-associated molecular pattern \\
\hline dsDNA & Double-stranded DNA \\
\hline ELISA & Enzyme-linked immunosorbent assay \\
\hline EMSA & Electrophoretic mobility shift assay \\
\hline GBP & Guanylate-binding protein \\
\hline FSC & Forward-scattered light \\
\hline ICSBP & Interferon consensus sequence binding protein \\
\hline IFN & Interferon \\
\hline IFNAR & Interferon- $\alpha / \beta$ receptor \\
\hline IRF & Interferon regulatory factor \\
\hline $\mathrm{LDH}$ & Lactate dehydrogenase \\
\hline LPS & Lipopolysaccharide \\
\hline MOI & Multiplicity of infection \\
\hline NAIP & NLR family apoptosis inhibitory protein \\
\hline NLR & $\begin{array}{l}\text { Nucleotide-binding oligomerization domain and leucine-rich repeat } \\
\text { receptor }\end{array}$ \\
\hline
\end{tabular}


PAMP

PRR

PYD

RT-PCR

SCV

siRNA

SPI

SSC

T3SS
Pathogen-associated molecular pattern

Pattern recognition receptor

Pyrin domain

Real-time PCR

Salmonella-containing vesicle

Small interfering RNA

Salmonella pathogenicity island

Side-scattered light

Type III secretion system 


\section{CHAPTER 1. INTRODUCTION}

\section{Background}

\section{Inflammasomes}

Inflammasomes are multimeric protein complexes that cleave pro-caspase- 1 into its active form in response to certain pathogen-associated molecular patterns (PAMPs) and danger-associated molecular patterns (DAMPs). The inflammasome complex comprises the sensor, adaptor, and enzyme. Members of nucleotide-binding oligomerization domain and leucine-rich repeat receptors (NLRs), absent in melanoma-2 (AIM2)-like receptors (ALRs), and pyrin serve as sensors. These proteins have caspase activation and recruitment domain (CARD) or pyrin domain (PYD) for homotypic interactions. ASC, which contains both CARD and PYD, functions as an adaptor for oligomerization of the complex. Inflammasome activation has two major consequences. Active caspase- 1 processes the pro-inflammatory cytokines IL-1 $\beta$ and IL-18 into their mature forms for extracellular release ${ }^{1}$. Also, caspase- 1 cleaves gasdermin D which forms pores in the plasma membrane to induce a form of inflammatory cell death termed pyroptosis $^{2-4}$.

NLRC4 (IPAF) was first identified in 2001 to interact with and activate caspase$1^{5}$. It was found that cytosolic flagellin derived from bacteria activated caspase- 1 through NLRC4 ${ }^{6,7}$. Because NLRC4 has a CARD capable of direct interaction with caspase-1, ASC is not required for NLRC4 inflammasome assembly and downstream cell death. However, production of cytokines by the NLRC4 inflamamsome is dependent on ASC ${ }^{8,9}$. The NLRC4 inflammasome is important for host defense against intracellular pathogens such as Salmonella ${ }^{10,11}$.

Although NLR family apoptosis inhibitory proteins (NAIPs) were previously discovered, the connection between NLRC4 and NAIPs was not identified until it was suggested that NAIP5 (BIRC1E) might trigger inflammasome assembly ${ }^{12}$. Now NAIPs are fully recognized as the direct receptors for bacterial protein recognition in the NLRC4 inflammasome ${ }^{13}$. NAIP1 detects bacterial type III secretion system (T3SS) needle and NAIP2 detects T3SS rod, while flagellin is sensed by NAIP5 and NAIP6 ${ }^{14-17}$. Humans have a single NAIP which is reported to interact with all three types of bacterial proteins ${ }^{18-20}$. It is not known how NAIPs or NLRC4 inflammasome activation may be regulated for cellular immunity.

\section{Interferon Signaling in Inflammasome Activation}

Interferon (IFN) signaling is known to play a pivotal role in inflammasome activation during microbial infection. Type I IFNs are indispensable for non-canonical activation of the NLRP3 inflammasome in response to Gram-negative bacteria. IFN- $\alpha / \beta$ 
receptor (IFNAR) signaling involves in upregulation of caspase-11 and is essential for its processing ${ }^{21,22}$. AIM2 inflammasome activation in response to Francisella is also dependent on type I IFNs ${ }^{23,24}$. Interferon regulatory factors (IRFs) are a central part of IFN signaling as they regulate the transcription of IFNs and IFN-inducible genes ${ }^{25}$. IRF1 is required for the induction of guanylate-binding proteins (GBPs) that liberate Francisella double-stranded DNA (dsDNA) into the cytosol, allowing AIM2 inflammasome activation ${ }^{26}$ (Figure 1-1).

IRF8 is an IRF family member previously known as IFN consensus sequence binding protein (ICSBP), which interacts with IRF1 ${ }^{27}$. Both factors are basally expressed in macrophages and further inducible by IFNs and lipopolysaccharide (LPS) ${ }^{28-31}$. Transcription of IL-12 and iNOS is cooperatively promoted by IRF1 and IRF8 ${ }^{32-35}$. Chromatin immunoprecipitation-sequencing (ChIP-seq) in bone marrow-derived macrophages (BMDMs) shows that IRF1 and IRF8 are co-recruited together at more than 4000 genomic regions after IFN- $\gamma$ treatment ${ }^{36}$. Although IRF8 is known to widely participate in antimicrobial defense, its role in inflammasomes is unknown.

\section{Hypothesis}

IRF1 is required for AIM2 inflammasome activation in response to Francisella infection, and multiple studies have shown functional interaction of IRF1 and IRF8 in mediating pathogen clearance. Thus, it is proposed that IRF8 may be required for promoting inflammasome activation during bacterial infection. 


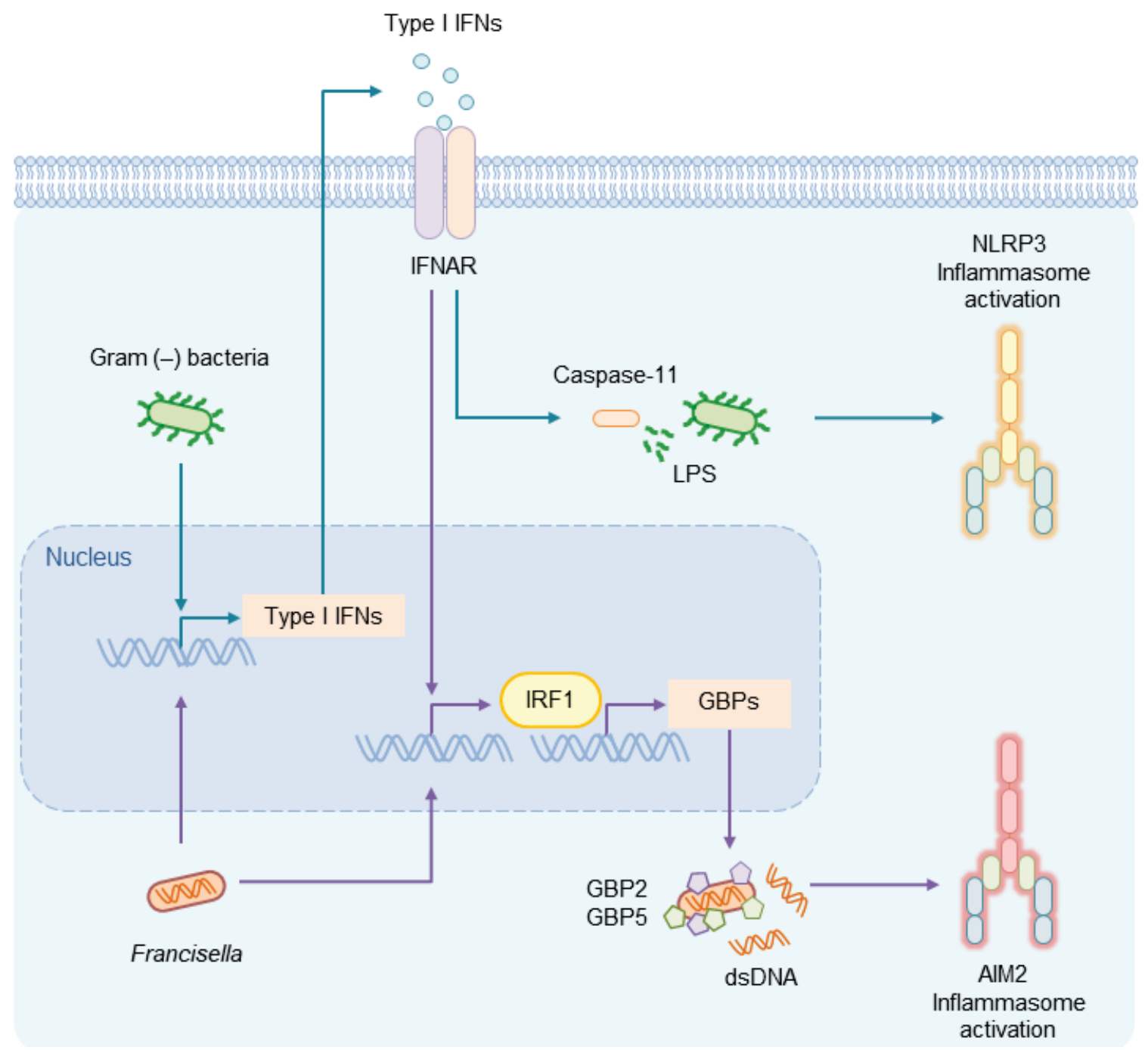

Figure 1-1. IFN signaling in inflammasome activation

Type I IFNs are produced in response to infection with Gram-negative bacteria, and signaling through IFNAR is required for caspase-11-dependent NLRP3 inflammasome activation. Cellular recognition of Francisella is dependent on type I IFN signaling and IRF1 for the transcription of GBPs. GBP2 and GBP5 localize to the bacterial wall of Francisella, releasing dsDNA which is recognized by the AIM2 inflammasome. 


\title{
CHAPTER 2. MATERIALS AND METHODS ${ }^{1}$
}

\author{
Experimental Models
}

Mice

$\operatorname{Irf} 8^{-/-}$mice (Jackson Laboratory, 018298), $\operatorname{Irfl}^{-/-}$mice $^{37}, \mathrm{Nlrp}^{-/-}$mice ${ }^{38}$, Nlrc 4 ${ }^{1-}$ mice ${ }^{6}, \mathrm{Nlrp}^{3^{-/}} \mathrm{Nlrc4^{-/ }}$ mice (generated by crossing $N l r p 3^{-/-}$and Nlrc4-/- mice in our facility), Aim2 $2^{-1-}$ mice ${ }^{39}$, Pyrin $^{-1-}$ mice ${ }^{40}$, and Naip $5^{-1-}$ mice ${ }^{41}$ (kindly provided by Dr. R. Vance), $I l 18^{-/} I l 1 r^{-/-}$mice (generated by crossing $I l 18^{-/-}$and $I l 1 r^{-/-}$mice in our facility), $G s d m^{-1-}$ mice (generated in our facility), $\operatorname{Casp1}^{-/-}$mice ${ }^{42}, \operatorname{Caspl}^{1^{-1}}$ mice $^{43}, \operatorname{Irf3}^{-/}$

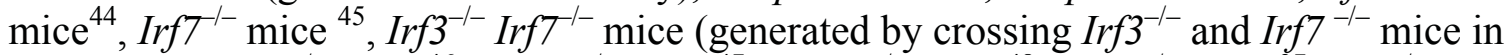

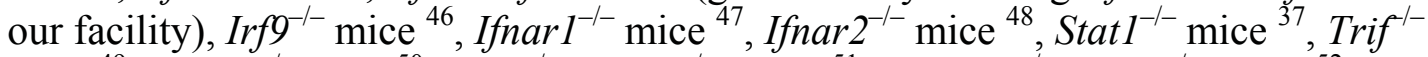

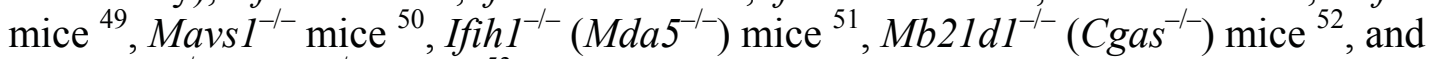
Tmem $173^{-1-}\left(\right.$ Sting $\left.{ }^{\mathrm{gt} / \mathrm{gt}}\right)$ mice ${ }^{53}$ have been described. All mice were bred at St. Jude Children's Research Hospital. Animal studies were conducted under protocols approved by St. Jude Children's Research Hospital's committee on the use and care of animals.

\section{Bone Marrow-Derived Macrophages (BMDMs)}

Primary BMDMs were grown for 6 days in DMEM (ThermoFisher Scientific, 11995-073) supplemented with 1\% non-essential amino acids (ThermoFisher Scientific, 11140-050), 10\% FBS (Biowest, S1620), 30\% medium conditioned by L929 mouse fibroblasts, and 1\% penicillin and streptomycin (ThermoFisher Scientific, 15070-063). BMDMs in antibiotic-free medium were seeded onto 12-well plates at a density of $10^{6}$ cells per well, followed by incubation overnight.

\section{Bacterial Culture}

Francisella novicida strain U112 was grown overnight under aerobic conditions at $37^{\circ} \mathrm{C}$ in BBL Trypticase Soy Broth (BD Biosciences, 211768) supplemented with $0.2 \%$ L-cysteine (ThermoFisher Scientific, BP376-100). Bacteria were subcultured (1:10) for 4 $\mathrm{h}$ at $37^{\circ} \mathrm{C}$ in fresh Trypticase Soy Broth supplemented with $0.2 \%$ L-cysteine and resuspended in PBS (ThermoFisher Scientific, 14190-250). Salmonella Typhimurium strain SL1344, isogenic mutants lacking SPI-1 ( $\triangle S P I-1)$, isogenic mutants lacking SPI-2 $(\triangle S P I-2)$, isogenic mutants lacking fliC and $f l j B(\triangle f l i C \Delta f l j B)$, Burkholderia thailandensis strain E264 (a gift from Dr. Joseph Mougous), and Pseudomonas aeruginosa strain PAO1 (a gift from Dr. Joseph Mougous) were inoculated into Luria-Bertani (LB) broth

\footnotetext{
${ }^{1}$ Modified from final submission with permission. Karki R*, Lee E*, Place D, Samir P, Mavuluri J, Sharma BR, et al. IRF8 Regulates Transcription of Naips for NLRC4 Inflammasome Activation. Cell. 2018 May 3;173(4):920-933.e13. (*Co-first author). https://doi.org/10.1016/j.cell.2018.02.055 [76].
} 
(MP Biomedicals, 3002-031) and incubated overnight under aerobic conditions at $37^{\circ} \mathrm{C}$. $S$. Typhimurium SL1344, all isogenic mutants of $S$. Typhimurium SL1344, $B$. thailandensis strain E264, and $P$. aeruginosa strain PAO1 were subcultured $(1: 10)$ for $3 \mathrm{~h}$ at $37^{\circ} \mathrm{C}$ in fresh LB broth to generate bacteria grown to log phase. Clostridium difficile strain $\mathrm{r} 20291 \mathrm{AB}-$ and AB+ strains were provided by Dr. N. Minton ${ }^{54}$. Strains were streaked onto brain heart infusion agar (BD Biosciences, 211065) and incubated overnight at $37^{\circ} \mathrm{C}$ in an anaerobic chamber. Single colonies were inoculated into tryptone-yeast extract medium and grown overnight at $37^{\circ} \mathrm{C}$ anaerobically. C. difficile cultures for cell stimulation were prepared by collecting supernatant via centrifugation followed by sterilization through a $0.2 \mu \mathrm{m}$ filter.

\section{Methods}

\section{Stimulation of BMDMs}

\section{Ligands}

For activation of the canonical NLRP3 inflammasome, BMDMs were primed for $4 \mathrm{~h}$ with $100 \mathrm{ng} / \mathrm{mL}$ ultrapure LPS from Salmonella minnesota R595 (InvivoGen, trrlsmlps) and were stimulated for $45 \mathrm{~min}$ with $5 \mathrm{mM}$ ATP (Roche, 10127531001). For transfection of DNA, each reaction consisted of $2 \mu \mathrm{g}$ of poly(dA:dT) (InvivoGen, trrlpatn) resuspended in PBS and mixed with $0.6 \mu \mathrm{L}$ of Xfect polymer in Xfect reaction buffer (Clontech Laboratories, Inc, 631318). After $10 \mathrm{~min}$, DNA complexes were added to BMDMs in Opti-MEM (ThermoFisher Scientific, 31985-070), followed by incubation for $5 \mathrm{~h}$. For IRF8 expression, BMDMs were stimulated with $100 \mathrm{ng} / \mathrm{mL}$ ultrapure LPS for indicated times. For bacterial protein transfection, $0.1 \mu \mathrm{g}, 0.5 \mu \mathrm{g}$, or $1 \mu \mathrm{g}$ of ultrapure flagellin from Salmonella Typhimurium (InvivoGen, tlrl-epstfla-5); $1 \mu \mathrm{g}$ of recombinant Salmonella Typhimurium PrgI (Mybiosource, MBS1177087); and $1 \mu \mathrm{g}$ of recombinant Salmonella Typhimurium PrgJ (Mybiosource, MBS2061410) were resuspended in PBS and mixed with $20 \mu \mathrm{L}$ of DOTAP (Roche, 11202375001) per reaction. The reaction mixture was incubated for $1 \mathrm{~h}$ and added to BMDMs in $500 \mu \mathrm{L}$ Opti-MEM.

\section{Bacterial infections}

For bacterial infection, the following conditions were used: F. novicida at an MOI of 100 for $20 \mathrm{~h}$ of incubation (for activation of caspase-1) and an MOI of 50 for 2, 8, 16, or $24 \mathrm{~h}$ of incubation (for expression of IRF8, GBP2, and GBP5); $S$. Typhimurium at an MOI of $0.01,0.1$, or 1 for $4 \mathrm{~h}$ of incubation (for activation of caspase-1) and an MOI of 0.01 for indicated times (for expression of IRF8); $\triangle S P I-1$ at an MOI of 1 for $4 \mathrm{~h}$ of incubation; $\triangle S P I-2$ at an MOI of 1 for $4 \mathrm{~h}$ of incubation; $\Delta f l i C \Delta f l j B$ at an MOI of 1 for 4 $\mathrm{h}$ of incubation; $B$. thailandensis at an MOI of $0.5,1$, or 5 for $4 \mathrm{~h}$ of incubation (for activation of caspase-1) and an MOI of 1 for indicated times (for expression of IRF8); and $P$. aeruginosa at an MOI of $0.5,1$, or 5 for $4 \mathrm{~h}$ of incubation. $50 \mu \mathrm{g} / \mathrm{ml}$ gentamicin (ThermoFisher Scientific, 15750-060) was added after $8 \mathrm{~h}$ (F. novicida) post-infection to 
kill extracellular bacteria. Cell culture supernatants were collected for enzyme-linked immunosorbent assays (ELISAs). Levels of lactate dehydrogenase released by cells were measured by performing a CytoTox 96 non-radioactive cytotoxicity assay according to the manufacturer's instructions (Promega, G1780).

\section{Small Interfering RNA (siRNA) Knockdown}

BMDMs were transfected for $48 \mathrm{~h}$ with siRNA from siGENOME smart pools by using the GenMute siRNA Transfection Reagent according to the manufacturer's instructions (SignaGen Laboratories, SL100568). The siGENOME SMARTpool siRNA specific for mouse Irf8 (Dharmacon, M-040737-00) was used in the study. A control siRNA pool was also used. Transfected cells were infected with $S$. Typhimurium as described above.

\section{Immunoblot Analysis}

BMDM cell lysates and culture supernatants were combined in caspase lysis buffer (containing protease inhibitors, phosphatase inhibitors, $10 \%$ NP- 40 , and $25 \mathrm{mM}$ DTT) and sample loading buffer (containing SDS and 2-mercaptoethanol) for immunoblot analysis of caspase-1. For immunoblot analysis of signaling, supernatants were removed and BMDMs were washed once with PBS, followed by lysis in RIPA buffer and sample loading buffer (containing SDS and 2-Mercaptoethanol). Proteins were separated by electrophoresis through $8-12 \%$ polyacrylamide gels. Following electrophoretic transfer of proteins onto PVDF membranes (Millipore, IPVH00010), nonspecific binding was blocked by incubation with $5 \%$ skim milk, then membranes were incubated with primary antibodies anti-caspase-1 (1:3,000 dilution; Adipogen, AG20B-0042), anti-IRF8 (1:1,000 dilution; Santa Cruz Biotechnology, sc-6058), anti-GBP2 (1:1,000 dilution; Proteintech, 11854-1-AP), anti-GBP5 (1:1,000 dilution; Proteintech, $13220-1-A P)$, or anti- $\beta$-actin (1:10,000 dilution; Proteintech, 66009-1-IG). Membranes were then washed and incubated with the appropriate horseradish peroxidase (HRP)conjugated secondary antibodies (1:5,000 dilution; Jackson Immuno Research Laboratories, anti-rabbit [111-035-047], anti-mouse [315-035-047], and anti-goat [705035-003]) for $1 \mathrm{~h}$. Proteins were visualized by using Luminata Forte Western HRP Substrate (Millipore, WBLUF0500).

\section{Real-Time PCR (RT-PCR) Analysis}

For bacterial stimulation, the following conditions were used: $S$. Typhimurium at an MOI of 0.01; and for flagellin transfection, $0.1 \mu \mathrm{g}$ of flagellin. RNA was extracted by using TRIzol (ThermoFisher Scientific, 15596026) according to the manufacturer's instructions. The isolated RNA was reverse-transcribed into cDNA by using a FirstStrand cDNA Synthesis Kit (Applied Biosystems, 4368814). RT-PCR was performed on 
an ABI 7500 RT-PCR instrument by using 2X SYBR Green (Applied Biosystems, 4368706) and the appropriate primers (Table 2-1).

\section{Cytokine Analysis}

Cytokines were measured by performing multiplex ELISA (Millipore, MCYTOMAG-70K) or ELISA for IL-18 (Invitrogen, BMS618-3) according to the manufacturer's instructions.

\section{Flow Cytometry}

The following monoclonal antibodies were used for flow cytometry cellular analyses: CD11b (M1/70; Affymetrix eBioscience, 48-0112-82) and F4/80 (BM8; BioLegend, 123109). The dilution factor used for these antibodies was 1:300. Flow cytometry data were acquired on a FACSCalibur flow cytometer (BD) and were analyzed by using FlowJo software (FlowJo, LLC and Illumina, Inc).

\section{Microarray}

Transcripts were profiled for $S$. Typhimurium-infected BMDMs obtained from WT and $\mathrm{IrfS}^{-/-}$mice. Total RNA (100 ng) was converted into biotin-labeled cRNA by using an Ambion Wild-Type Expression kit (ThermoFisher Scientific, 4411973) and was hybridized to a Affymetrix GeneChip Mouse Gene 2.0 ST Array (ThermoFisher Scientific, 902119). After chips were stained and washed, array signals were normalized and transformed into $\log 2$ transcript expression values by using the robust multi-array average algorithm (Partek Genomics Suite version 6.6). Differential expression was defined by application of a difference in expression of 0.5 -fold ( $\log 2$ signal) between conditions. Lists of differentially expressed transcripts were analyzed for 'functional enrichment' by using the DAVID bioinformatics database ${ }^{55}$ and Ingenuity Pathways Analysis software (Qiagen). The microarray dataset was deposited under the accession code GSE110452.

\section{Network Analysis}

An interaction network was generated by using the GeneMANIA Cytoscape plugin with default settings 56 .

\section{Chromatin Immunoprecipitation-Sequencing (ChIP-Seq)}

FASTQ files corresponding to input (GEO Accession number: GSM1721243), IRF8 ChIP (GEO Accession number: GSM1721244) ${ }^{57}$ were downloaded from the 
Table 2-1. RT-PCR primer sequences

\begin{tabular}{|c|c|c|}
\hline Gene & Strand & Sequence \\
\hline \multirow[t]{2}{*}{ Naip1 } & Forward & 5'-TGCCCAGTATATCCAAGGCTA-3' \\
\hline & Reverse & 5'-AGACGCTGTCGTTGCAGTAAG-3' \\
\hline \multirow[t]{2}{*}{ Naip2 } & Forward & 5'-TTTTGTGAATCCCTGGGTCA-3' \\
\hline & Reverse & 5'-TGTAGAAAAGGCCTGCTTTGA-3' \\
\hline \multirow[t]{2}{*}{ Naip5 } & Forward & 5'-AAGGAGATGACCCCTGGAAG-3' \\
\hline & Reverse & 5'-TGACCCAGGACTTCACAAAA-3' \\
\hline \multirow[t]{2}{*}{ Naip6 } & Forward & 5'-TTTTGTGAAGTCCTGGGTCAG-3' \\
\hline & Reverse & 5'-CAATGTCCTTTTTGCCAGTG-3' \\
\hline \multirow[t]{2}{*}{ Nlrc4 } & Forward & 5'-CAGGTGGTCTGATTGACAGC-3' \\
\hline & Reverse & 5'-CCCCAATGTCAGACAAATGA-3' \\
\hline \multirow[t]{2}{*}{$\operatorname{Irf8}$} & Forward & 5'-GATCGAACAGATCGACAGCA-3' \\
\hline & Reverse & 5'-GCTGGTTCAGCTTTGTCTCC-3' \\
\hline \multirow[t]{2}{*}{ Nlrp3 } & Forward & 5'-TGCAGAAGACTGACGTCTCC-3' \\
\hline & Reverse & 5'-CGTACAGGCAGTAGAACAGTTC-3' \\
\hline \multirow[t]{2}{*}{ Gapdh } & Forward & 5'-CGTCCCGTAGACAAAATGGT-3' \\
\hline & Reverse & 5'-TTGATGGCAACAATCTCCAC-3' \\
\hline \multirow[t]{2}{*}{ Hprt } & Forward & 5'-CTCATGGACTGATTATGGACAGGAC-3' \\
\hline & Reverse & 5'-GCAGGTCAGCAAAGAACTTATAGCC-3' \\
\hline
\end{tabular}


Sequence Read Archive database by using SRA toolkit. FASTQ files were uploaded to DNA Nexus (St. Jude Cloud), and sequence reads were mapped against the GRCm38/mm10 genome build. Bedgraph files corresponding to IRF4 ChIP-seq experiment were downloaded from GEO database (GEO Accession number: GSE85172) ${ }^{58}$. BED files containing the enrichment scores for SPI1 binding were also

downloaded from GEO database (GEO Accession number: GSE77886) ${ }^{36}$. The result was visualized using Integrative Genomics Viewer (IGV) ${ }^{59}$.

\section{ChIP-PCR}

WT BMDMs were cross-linked with 1\% paraformaldehyde for $10 \mathrm{~min}$ followed by glycin quenching. Samples were washed with ice cold PBS and scraped in PBS supplemented with protease inhibitors. Cell pellets were incubated with SDS lysis buffer for $10 \mathrm{~min}$ on ice followed by sonication using Covaris sonicator to obtain the desired fragment length (300 bps to $700 \mathrm{bps}$ ). An equal amount of DNA was used for IgG (control) (Cell Signaling Technology, 2729) and IRF8 (Cell Signaling Technology, 5628) immunoprecipitation. Immunoprecipitated DNA was eluted in elution buffer and amplified with primers for Naip2 and Naip5 (Table 2-2).

\section{Luciferase Assay}

The Naip2 and Naip5 promoter fragments $\mathrm{nt}-1 \mathrm{~kb}$ to $+1 \mathrm{~kb}$, were amplified by PCR using mouse genomic DNA as a template and inserted into the KpnI and XhoI sites of the luciferase reporter plasmid pGL4.17 basic vector (Promega, E6721) yielding reporter constructs pGL4.17 Naip2 and pGL4.17 Naip5 respectively. HEK293T cells (ATCC , 3216) were co-transfected with the mixture of the indicated luciferase reporter plasmid and pRL-TK-Renilla luciferase (Promega, E2241) plasmid using FuGENE (Promega, E2311) according to manufacturer's instructions. For inducing IRF8 expression, cells were transfected with pCMV6-mIRF8 vector (Origene, MR206748) and luciferase activity was quantified $48 \mathrm{~h}$ after transfection with the Dual-Luciferase Reporter Assay System (Promega, E1910) according to the manufacturer's instructions. pcDNA3.1 (Invitrogen, V79020) was used as empty vector control.

\section{Electrophoretic Mobility Shift Assay (EMSA)}

Nuclear extracts from BMDMs were prepared using NP-40 lysis buffer. EMSA was performed using Light Shift Chemiluminescent EMSA kit (ThermoFisher Scientific, 20148). Analysis of IRF8 binding to predicted sites was performed using annealed biotin labeled oligonucleotide probes in a $20 \mu \mathrm{l}$ reaction mixture for $20 \mathrm{~min}$ at room temperature. Samples were run on a non-denaturing $5 \%$ polyacrylamide gel and transferred to a nylon membrane (ThermoFisher Scientific, 77016), cross-linked in UV. 
Table 2-2. ChIP-PCR primer sequences

\begin{tabular}{lll}
\hline Gene & Strand & Sequence \\
\hline Naip2 & Forward & 5'-TTTCAACCTTACTACACTTTCAATCAAATAGAA-3' \\
& Reverse & 5'-ATAGATAGATAGATATGGATATATAACC-3' \\
Naip5 & Forward & 5'-AGTGCTGACACATTTGATGCCACCAATGCA-3' \\
& Reverse & 5'-GCCCCCTTGCTGCTGATGCTCTGTGACCAG-3' \\
\hline
\end{tabular}

\section{Complementation}

Primary mouse BMDMs were transfected with the control pcDNA3.1 or pCMV6mIRF8 vector (Origene, MR206748) by nucleofection (ThermoFisher Scientific, MPK10025) following the manufacturer's instructions.

\section{Animal Infection}

Frozen stocks of $S$. Typhimurium or $B$. thailandensis were prepared from LBgrown $S$. Typhimurium or $B$. thailandensis, quantified prior to infection, and diluted in PBS for infections. For $S$. Typhimurium infection, mice were injected intraperitoneally with $10^{3} \mathrm{CFU}$ in $200 \mu \mathrm{L}$ PBS. For $B$. thailandensis infection, mice were lightly anesthetized with isoflurane and inoculated intranasally with $5 \times 10^{4} \mathrm{CFU}$ in $50 \mu \mathrm{L}$ PBS. After 3 days of $S$. Typhimurium or 2 days of $B$. thailandensis infection, lungs, liver, and spleen were collected and then homogenized for $2 \mathrm{~min}$ in PBS with metal beads by using a TissueLyser II apparatus (Qiagen). CFU values were quantified by plating lysates onto LB agar, followed by incubation overnight. No randomization or blinding was used. Formalin preserved lungs were processed and embedded in paraffin according to standard procedures. Sections $(5 \mu \mathrm{m})$ were stained with H\&E and examined.

\section{Statistical Analysis}

GraphPad Prism 6.0 software was used for data analysis. Data are shown as mean \pm SEM. Statistical significance was determined by $t$ tests (two-tailed) for two groups or ANOVA (with Dunnett's multiple comparisons test, Dunn's multiple comparisons test, or Tukey's multiple comparisons test) for three or more groups. Survival curves were compared with the log-rank test outcome. P values less than 0.05 were considered to be statistically significant. 


\section{CHAPTER 3. RESULTS ${ }^{2}$}

\section{IRF8 Is Dispensable for AIM2, NLRP3, and Pyrin Inflammasome Activation}

Francisella tularensis, the agent responsible for causing tularemia in humans, uses multiple strategies to evade immune surveillance ${ }^{60}$. Importantly, AIM2 detects the double-stranded DNA (dsDNA) of the bacterium following its exposure in cytosol ${ }^{24,39} . F$. tularensis subspecies novicida ( $F$. novicida) triggered AIM2 inflammasome-dependent cleavage of pro-caspase-1 (p45) into active caspase-1 (p20), subsequently producing mature cytokines IL-1 $\beta$ and IL-18, and inducing cell death in unprimed WT BMDMs. $\operatorname{Irf} 8^{-/-}$BMDMs were equally capable of cleaving caspase- 1 as WT, producing IL- $1 \beta$ and IL-18, and pyroptosis following $F$. novicida infection, suggesting IRF8 had no role in AIM2 inflammasome activation (Figure 3-1A, B, and C and Figure 3-2A). Because IRF8 is involved in the development of immune cells ${ }^{61}$, we examined the macrophage markers F4/80 and CD11b. The enrichment of double-positive cell populations in $\operatorname{Irf} 8^{-/}$ BMDMs was comparable to that in WT BMDMs, indicative of normal in vitro macrophage differentiation (Figure 3-3A).

Our group previously demonstrated that IRF1 is required to induce GBP2 and GBP5, which mediate killing of $F$. novicida and liberation of bacterial DNA to induce AIM2 inflammasome activation ${ }^{26}$. In $\operatorname{Irf~}^{-1-}$ BMDMs, the protein levels of GBP2 and GBP5 were similar to those of control (Figure 3-3B). IRF1 is dispensable for cytosolic poly(dA:dT)-mediated AIM2 inflammasome activation ${ }^{26}$. To investigate the requirement of IRF8 in response to poly(dA:dT), we transfected poly(dA:dT) into WT and Irf $8^{-1-}$ BMDMs. Caspase-1 activation, IL-18 levels, and cell death in poly(dA:dT)-transfected BMDMs from WT or Irf $8^{-/-}$mice were comparable (Figure 3-1D, E, and F and Figure 3-2B).

Similarly, we did not observe a significant difference in canonical NLRP3 inflammasome (Figure 3-1G, H, and I and Figure 3-2C) or non-canonical NLRP3 inflammasome activation (Figure 3-1J, K, and $\mathbf{L}$ and Figure 3-2D). The levels of inflammasome-independent cytokines (IL-6, TNF, and KC) were largely unaffected by the absence of IRF8 (Figure 3-2).

Pyrin inflammasome activation is triggered by the inactivation of Rho GTPases, which can be caused by bacterial cytotoxins ${ }^{62}$. Toxin from $C$. difficile $\mathrm{AB}+$ strain induced Pyrin inflammasome activation that was not mediated by IRF8 (Figure 3-1M, N, and $\mathbf{O}$ ). These results excluded the requirement of IRF8 for AIM2, NLRP3, and Pyrin inflammasome activation.

\footnotetext{
2 Modified from final submission with permission. Karki R*, Lee E*, Place D, Samir P, Mavuluri J, Sharma BR, et al. IRF8 Regulates Transcription of Naips for NLRC4 Inflammasome Activation. Cell. 2018 May 3;173(4):920-933.e13. (*Co-first author). https://doi.org/10.1016/j.cell.2018.02.055 [76].
} 
Figure 3-1. IRF8 does not affect the activation of AIM2, NLRP3, or Pyrin inflammasomes

(A) Immunoblot analysis of pro-caspase-1 (p45) and the cleaved caspase-1 (p20) in WT or mutant BMDMs left untreated/uninfected (Media) or infected with F. novicida (multiplicity of infection [MOI], 100) and collected after $20 \mathrm{~h}$.

(B) Assessment of IL-18 release by enzyme-linked immunosorbent assay (ELISA) following $F$. novicida infection.

(C) Images of BMDMs under light microscopy after $F$. novicida infection. The arrows indicate pyroptotic cells.

(D-F) Immunoblot analysis of caspase-1, IL-18 release, and cell images of BMDMs after transfection with poly $(\mathrm{dA}: \mathrm{dT})$.

(G-I) Immunoblot analysis of caspase-1, IL-18 release, and cell images of LPS-primed BMDMs stimulated with ATP.

(J-L) Immunoblot analysis of caspase-1, IL-18 release, and cell images of BMDMs primed with LPS and followed by LPS transfection.

(M-O) Immunoblot analysis of caspase-1, IL-18 release, and cell images of BMDMs following treatment of toxin from $C$. difficle $\mathrm{AB}+$ strain.

Scale bars, $100 \mu \mathrm{m}(\mathrm{C}, \mathrm{F}, \mathrm{I}, \mathrm{L}$ and $\mathrm{O})$, NS, not significant; $* * \mathrm{P}<0.01, * * * \mathrm{P}<0.001$ and $* * * * \mathrm{P}<0.0001$ (One-way ANOVA with Dunnett's multiple comparisons test). Data are representative of 3 (A, C, D, F, G, I, J, L, M, and O) or from $3(\mathrm{~B}, \mathrm{E}, \mathrm{H}, \mathrm{K}$, and N) independent experiments (mean $\pm \mathrm{SEM}$ ). 

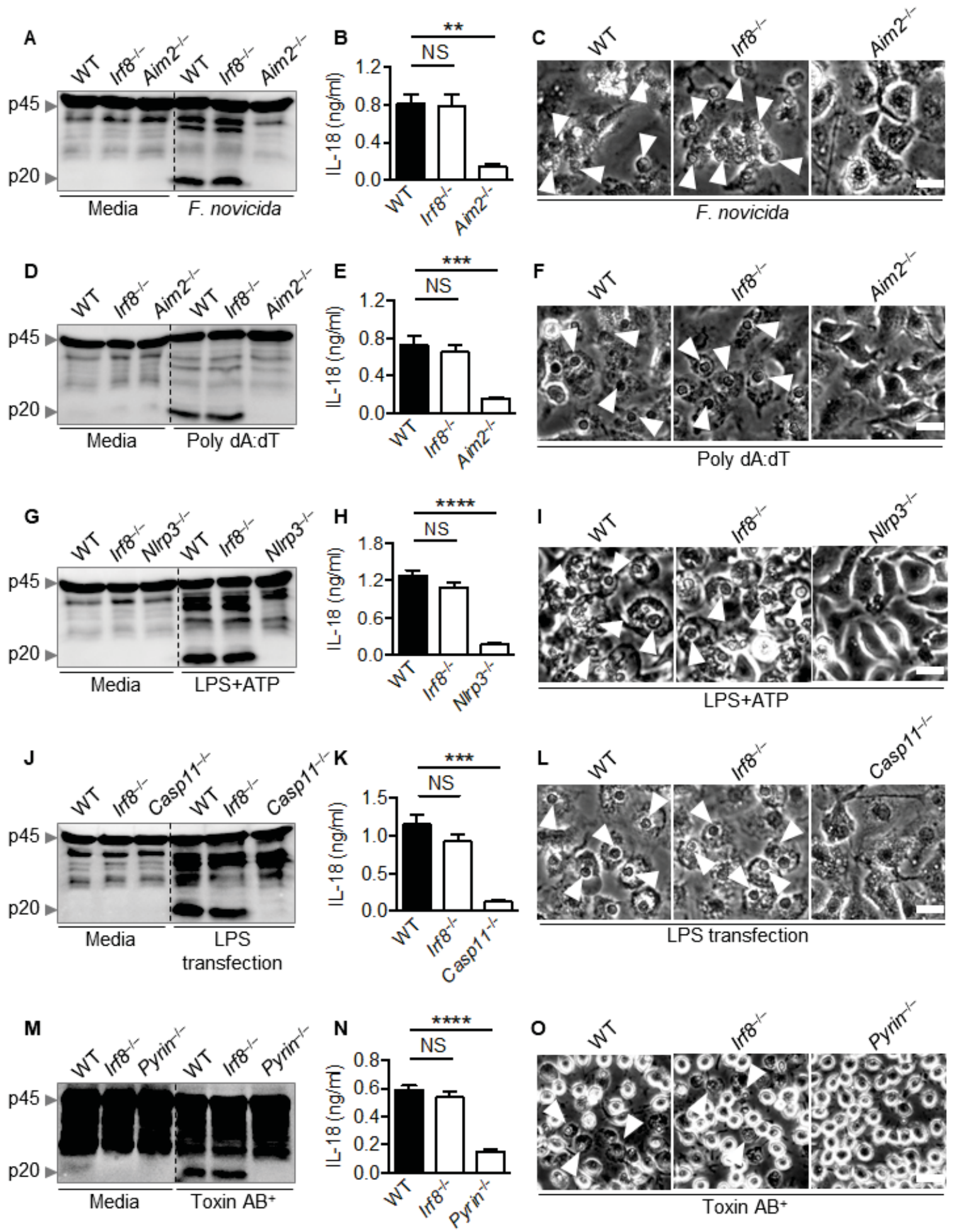
Figure 3-2. Inflammasome-independent cytokine secretion and cell death in response to various stimuli are not altered by IRF8

(A) Release of cytokines IL-1 $\beta$, IL-6, TNF and lactate dehydrogenase (LDH) in BMDMs after infection with $F$. novicida (MOI, 100).

(B) Release of IL-6, TNF, KC and LDH in BMDMs transfected with poly(dA:dT).

(C) Release of IL-1 $\beta$, IL-6, TNF and LDH in BMDMs primed with LPS and stimulated with ATP.

(D) Release of IL-6, TNF, KC and LDH in BMDMs primed with LPS and transfected with LPS.

NS, not significant; **P $<0.01$ and $* * * \mathrm{P}<0.001$ (One-way ANOVA with Dunnett's multiple comparisons test). Data are from 3 independent experiments (mean $\pm \mathrm{SEM}$ ). 
A
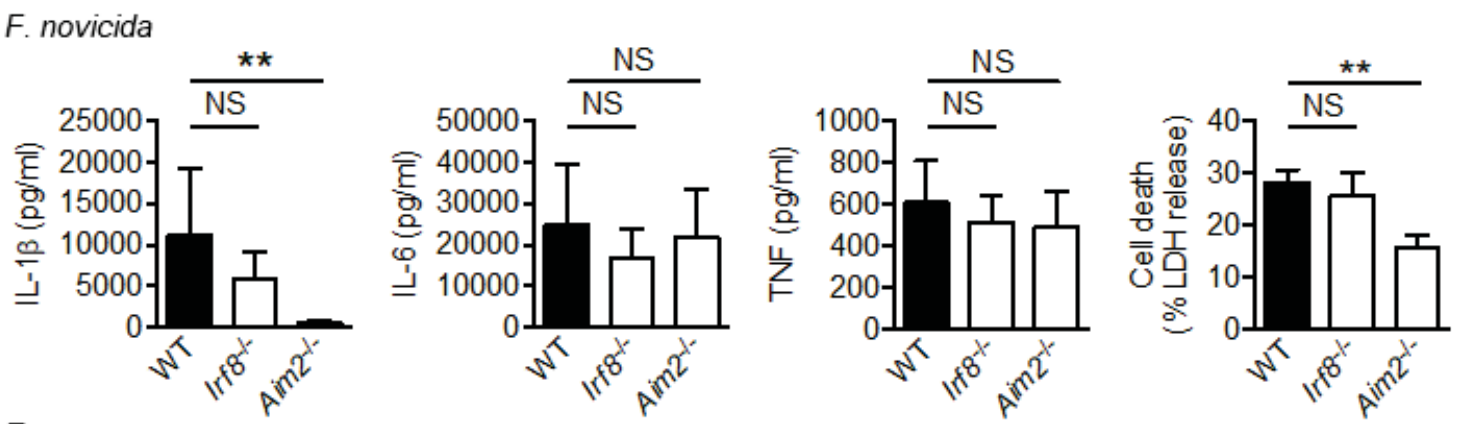

Poly dA:dT
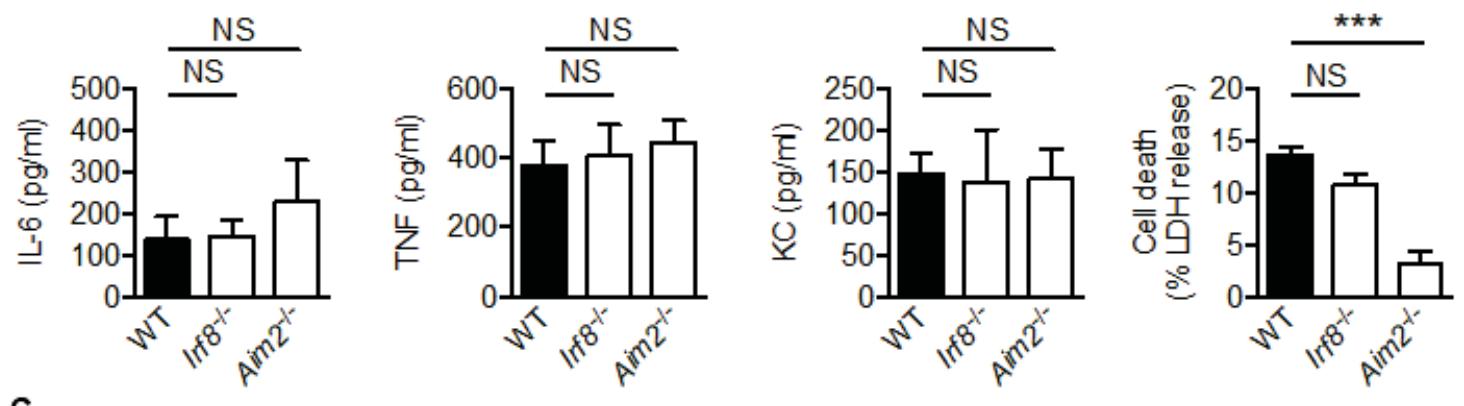

LPS+ATP
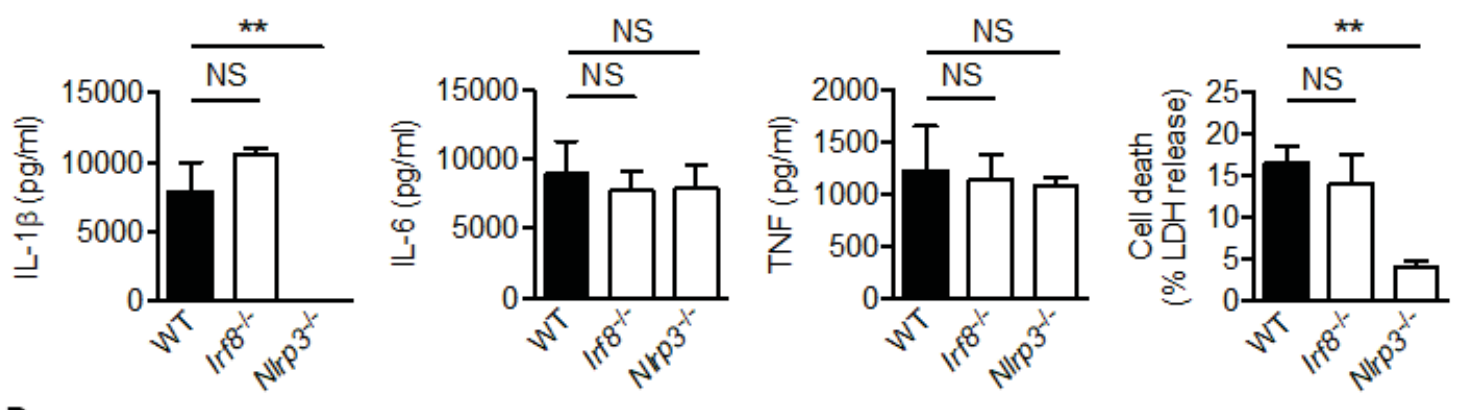

LPS transfection
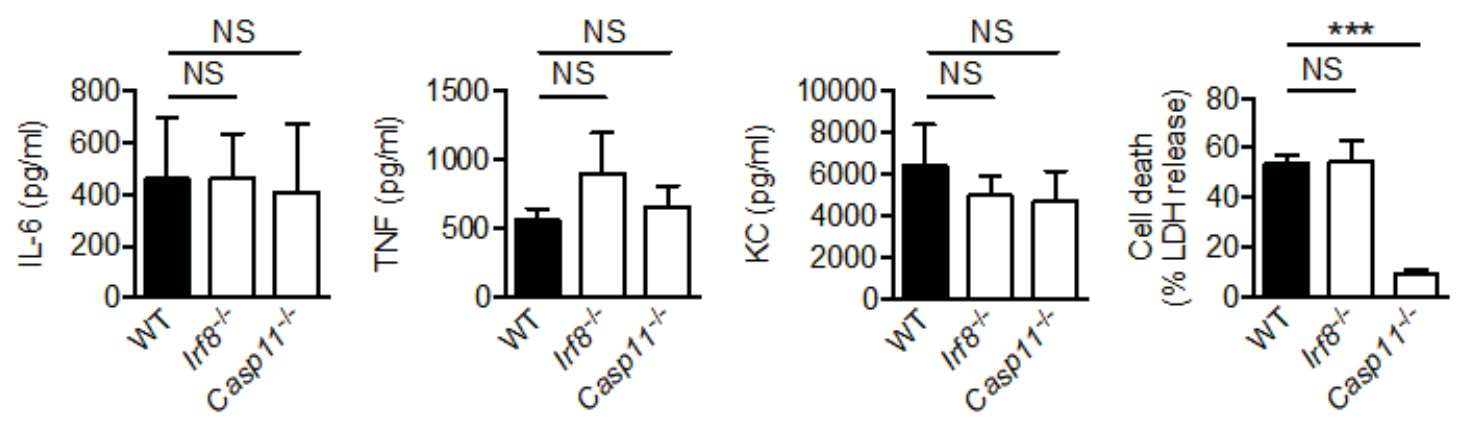

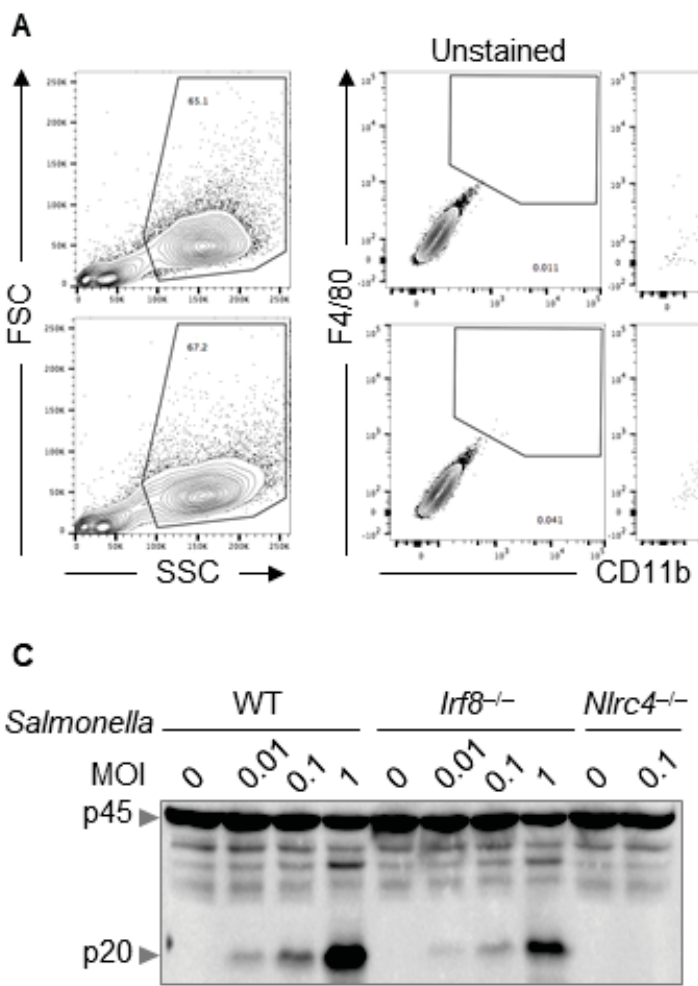

C

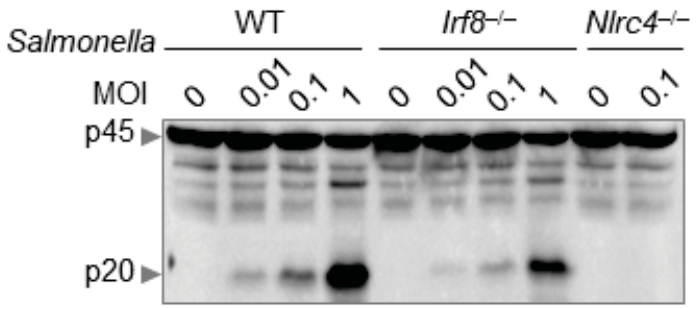

E

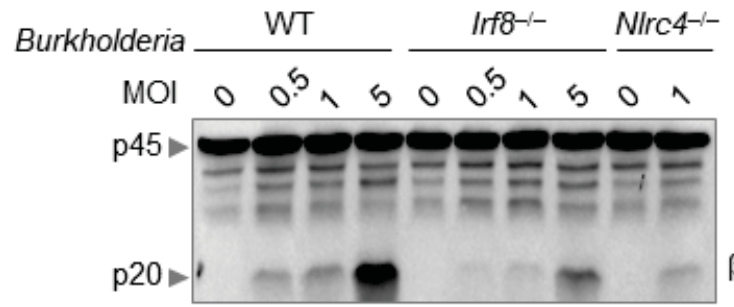

Stained

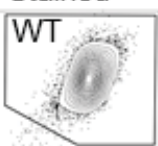

98.9

$+7$

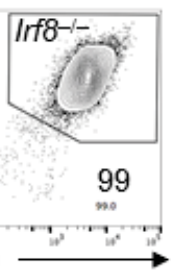

B

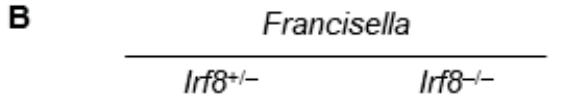

Time (h) $0281^{6} 2^{\alpha} \circ 281^{6} 2^{\alpha}$

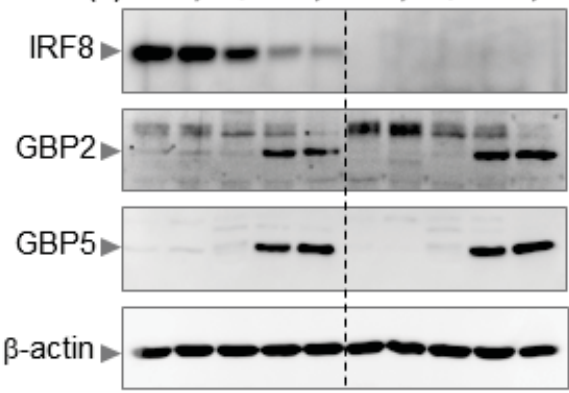

D

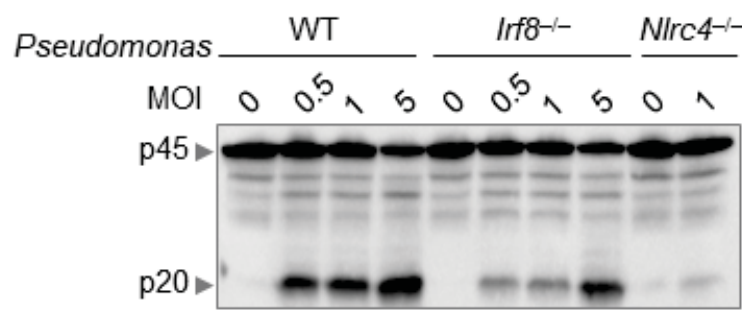

$\mathbf{F}$

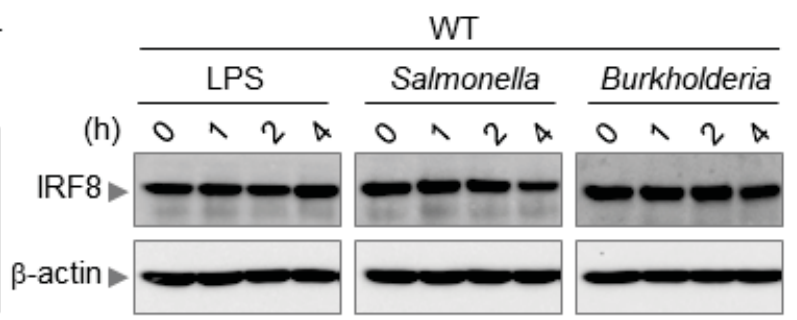

Figure 3-3. IRF8 is necessary for NLRC4 inflammasome activation in various doses of bacterial infection

(A) Flow cytometric analysis of side-scattered light (SSC), forward-scattered light (FSC); and expression of F4/80 and CD11b of BMDMs generated from WT and $\operatorname{Irf} 8^{-/-}$mice.

(B) Immunoblot analysis of IRF8, GBP2, GBP5, and $\beta$-actin (loading control) in BMDMs at various times after infection with $F$. novicida.

(C-E) Immunoblot analysis of caspase-1 in BMDMs that were infected with multiple MOIs of $S$. Typhimurium, $P$. aeruginosa, or $B$. thailandensis.

(F) Immunoblot analysis of IRF8 in BMDMs stimulated with LPS or infected with $S$. Typhimurium or $B$. thailandensis.

Data are representative of 2 independent experiments. 


\section{IRF8 Is Required for Optimal NLRC4 Inflammasome Activation}

\section{Salmonella Typhimurium-Dependent NLRC4 Inflammasome Activation}

The NLRC4 inflammasome is critical for determining the response to bacterial pathogens that have gained access to the cytosol. Salmonella, a Gram-negative bacteria whose primary route of infection in mice and humans is through the gastrointestinal tract, was one of the first microbes identified to activate the NLRC4 inflammasome ${ }^{8}$. Other bacterial species characterized to engage NLRC4 inflammasome are Pseudomonas aeruginosa, Burkholderia thailandensis, and Legionella pneumophila ${ }^{12,15,63,64}$. We infected WT BMDMs with Salmonella enterica subspecies enterica serovar Typhimurium ( $S$. Typhimurium), which resulted in robust caspase-1 activation (Figure 3-4A). Surprisingly, reduced caspase-1 activation was observed in infected $\operatorname{Irf} 8^{-1-}$ BMDMs (Figure 3-4A and Figure 3-3C). IL-18 and IL-1 $\beta$ production was dampened, with fewer pyroptotic cells (Figure 3-4B, C and Figure 3-5A). Collectively, all features of caspase-1 activation were attenuated in the absence of IRF8 in response to $S$. Typhimurium infection.

Many pathogenic bacteria including Salmonella species harbor flagella and the evolutionarily related T3SS as important virulence mechanisms, which activate the NLRC4 inflammasome. Flagellin monomers form the filamentous flagellum that confers motility. The T3SS is composed of a basal body, connecting rod, and needle that altogether serves as a molecular syringe to inject various effector proteins into the host cytosol, inflicting intracellular perturbations beneficial to the invasion of the bacterium ${ }^{65-67}$. Previous studies have utilized flagellin-mutant $S$. Typhimurium to delineate the specific role of flagellin in activating the NLRC4 inflammasome ${ }^{6,7} . S$. Typhimurium lacking flagellin proteins FliC and $\mathrm{FljB}(\triangle f l i C \Delta f l j B)$ was still able to elicit caspase-1 activation and cell death in WT BMDMs that was largely dependent on NLRC4 (Figure 3-4D and Figure 3-5B, C). $\Delta f l i C \Delta f l j B$ can activate the NLRC4 inflammasome alternatively by T3SS ${ }^{15}$. Infection with $\Delta f l i C \Delta f l j B$ in $\operatorname{Irf} 8^{-/-} \mathrm{BMDMs}$ revealed reduced caspase-1 activation, IL-18 release, and cell death, suggesting that IRF8 is necessary for T3SS-dependent NLRC4 inflammasome activation (Figure 3-4D, F and Figure 3-5B, C). The residual caspase-1 cleavage observed in cells lacking NLRC4 might be due to NLRP3 inflammasome activation ${ }^{9,68}$. To address this question, we infected $N l r p 3^{--} N l r c 4^{-1-}$ BMDMs with $\triangle f l i C \Delta f l j B$, which exhibited defective caspase-1 activation, IL-18 production, and cell death (Figure 3-4E, F and Figure 3-5B, C).

There are two versions of Salmonella T3SS that are encoded separately by Salmonella pathogenicity island-1 (SPI-1) and SPI-2. SPI-1 T3SS is expressed to promote cell invasion in early stages of infection until Salmonella establishes its replicative niche in the phagocytic compartment Salmonella-containing vesicle (SCV), where it downregulates flagellin and SPI-1 T3SS expression and switches to SP1-2 $\mathrm{T} \mathrm{SS}^{65}$. SPI-1 was critical for inflammasome activation in response to $S$. Typhimurium because the $\triangle S P I-1$ strain was unable to activate caspase-1 (Figure 3-4G). In contrast, $\triangle S P I-2$ infection was able to induce NLRC4 inflammasome-mediated caspase-1 
Figure 3-4. IRF8 is necessary for NLRC4 inflammasome activation induced by bacterial infection

(A-C) Immunoblot analysis of caspase-1, IL-18 release, and cell images of BMDMs that were infected with $S$. Typhimurium (MOI, 0.1) and collected after $4 \mathrm{~h}$.

(D and E) Immunoblot analysis of caspase-1 in BMDMs that were infected with $\triangle f l i C \triangle f l j B S$. Typhimurium $(\triangle f l i C \Delta f l j B)(\mathrm{MOI}, 1)$ and collected after $4 \mathrm{~h}$.

(F) Assessment of IL-18 levels in cell supernatants following $\Delta$ fliC $\Delta f l j B$ infection.

(G) Immunoblot analysis of caspase-1 in BMDMs that were infected with $\triangle S P I-1 S$.

Typhimurium ( $\triangle S P I-1)(\mathrm{MOI}, 1)$ and collected after $4 \mathrm{~h}$.

(H) Immunoblot analysis of caspase-1 in BMDMs that were infected with $\triangle S P I-2 S$.

Typhimurium ( $\triangle S P I-2)(\mathrm{MOI}, 1)$ and collected after $4 \mathrm{~h}$.

(I) Assessment of IL-18 levels in cell supernatants following $\triangle S P I-2$ infection.

(J-L) Immunoblot analysis of caspase-1, IL-18 release, and cell images of BMDMs after

$P$. aeruginosa (MOI, 1) infection for $4 \mathrm{~h}$.

(M-O) Immunoblot analysis of caspase-1, IL-18 release, and cell images of BMDMs

after $B$. thailandensis (MOI, 1) infection for $4 \mathrm{~h}$.

Scale bars, $100 \mu \mathrm{m}(\mathrm{C}, \mathrm{L}$ and $\mathrm{O})$, NS, not significant; $* \mathrm{P}<0.05, * * \mathrm{P}<0.01, * * * \mathrm{P}<$ 0.001 and $* * * * \mathrm{P}<0.0001$ (One-way ANOVA with Dunnett's multiple comparisons test).

Data are representative of 3 (A, C, D, E, G, H, J, L, M, and O) or from 3 (B, F, I, K, and $\mathrm{N})$ independent experiments (mean $\pm \mathrm{SEM}$ ). 

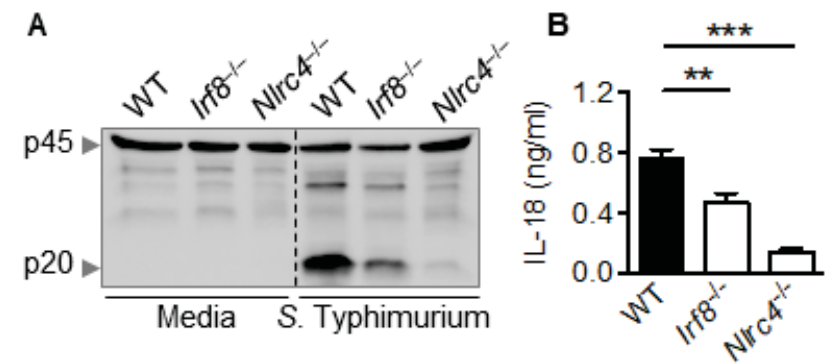

D
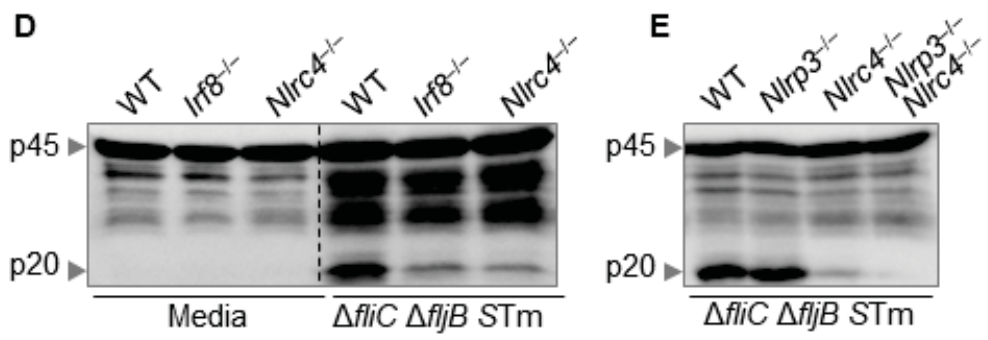

C

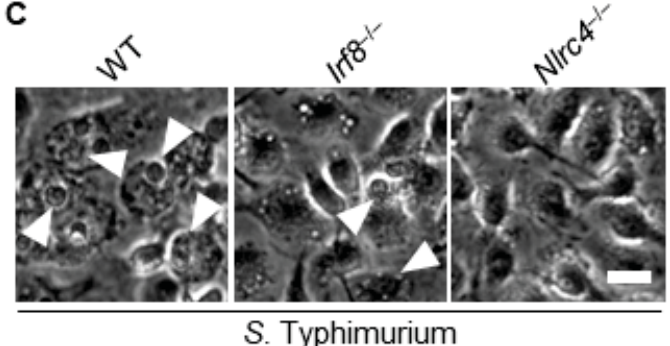

S. Typhimurium

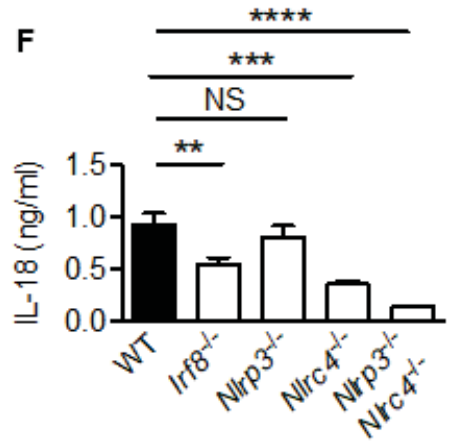

G
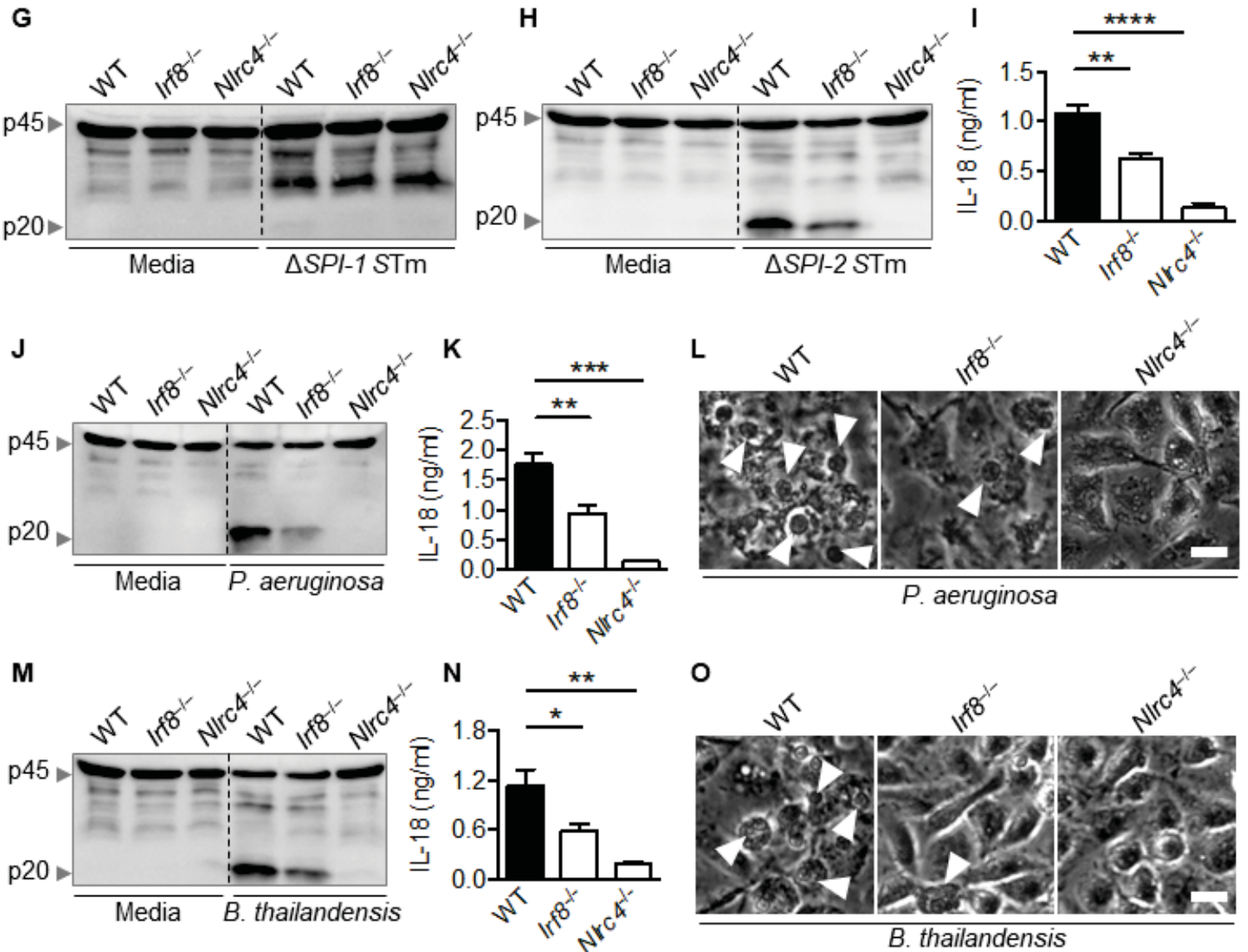
Figure 3-5. IRF8 is required for NLRC4 inflammasome activity but not for inflammasome-independent cytokine release after various bacterial infections (A) Release of IL-1 $\beta$, TNF, IL-6 and LDH in BMDMs after infection with $S$. Typhimurium (MOI, 0.1). (B and C) Microscopic images and cell death analysis of BMDMs infected with $\triangle f l i C \Delta f l j B(\mathrm{MOI}, 1)$ or $\triangle S P I-2$ (MOI, 1).

(D) Release of IL-1 $\beta$, TNF, IL-6 and LDH in BMDMs after infection with $P$. aeruginosa (MOI, 1).

(E) Release of IL-1 $\beta$, TNF, IL-6 and LDH in BMDMs after infection with $B$. thailandensis (MOI, 1).

Scale bars, $100 \mu \mathrm{m}(\mathrm{B}), \mathrm{NS}$, not significant; $* \mathrm{P}<0.05, * * \mathrm{P}<0.01, * * * \mathrm{P}<0.001$ and $* * * * \mathrm{P}<0.0001$ (One-way ANOVA with Dunnett's multiple comparisons test). Data are representative of $3(\mathrm{~B})$ or from 3 (A and $\mathrm{C}-\mathrm{E}$ ) independent experiments (mean $\pm \mathrm{SEM}$ ). 
A

S. Typhimurium
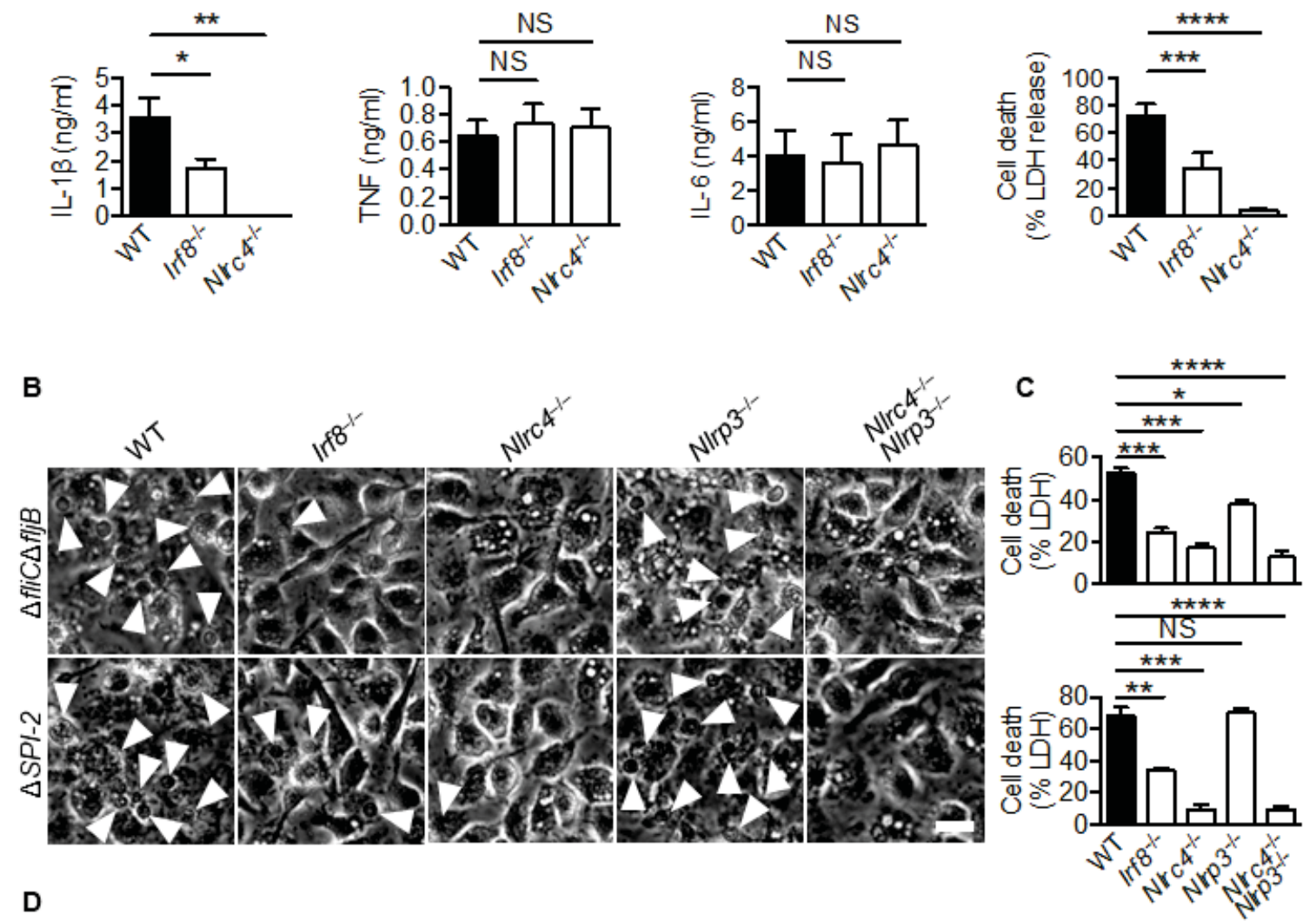

D
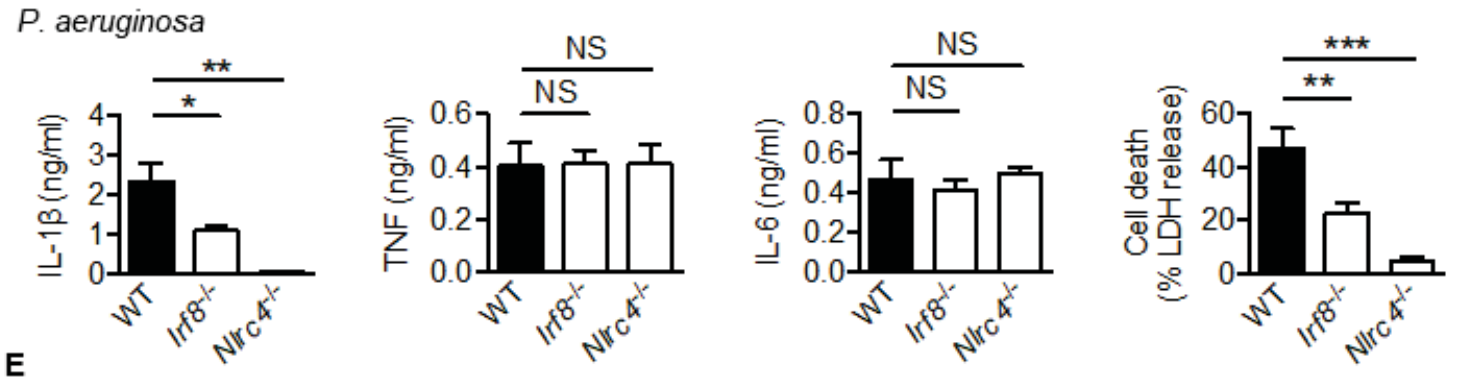

B. thailandensis
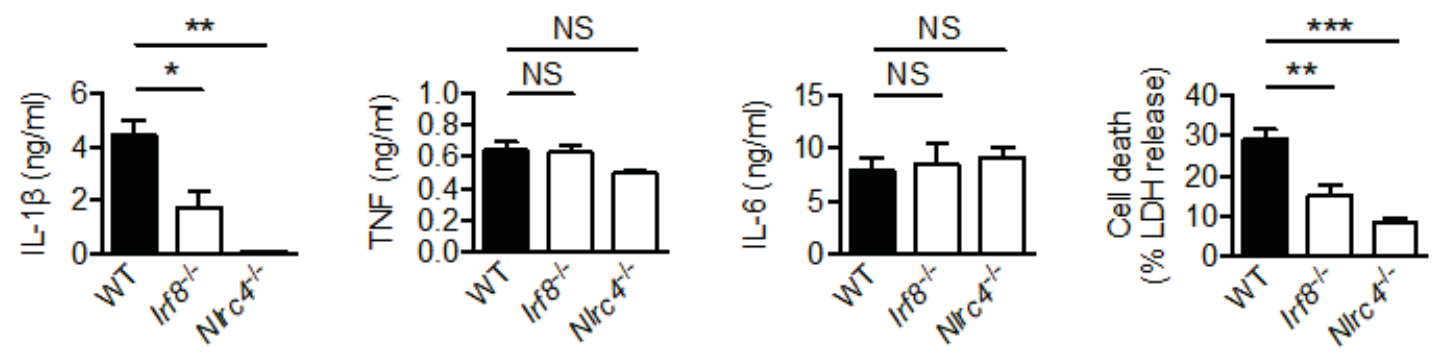
activation, IL-18 secretion, and pyroptosis in WT BMDMs, and to a lesser degree, in Irf $8^{-/-}$BMDMs (Figure 3-4H, I and Figure 3-5B, C). These results suggest that IRF8 plays a role in NLRC4 inflammasome activation that is dependent on functional SPI-1 T3SS of Salmonella.

\section{P. aeruginosa and $B$. thailandensis-Dependent NLRC4 Inflammasome Activation}

We further investigated the contribution of IRF8 to NLRC4 inflammasome activation by infecting BMDMs with other bacteria that engage the NLRC4 inflammasome. P. aeruginosa activated caspase-1 in WT BMDMs, leading to IL-18 and IL-1 $\beta$ secretion and pyroptotic cell death. Indeed, Irf $8^{-/}$BMDMs had less caspase-1 activation, IL-18 and IL-1 $\beta$, and cell death than WT (Figure 3-4J, K, and L, Figure 3-3D, and Figure 3-5D). Consistently, the extent of NLRC4 inflammasome activity was reduced in $\operatorname{Irf} 8^{-/-}$BMDMs after infection with $B$. thailandensis (Figure 3-4M, N, and $\mathbf{O}$, Figure 3-3E, and Figure 3-5E). However, there was no defect in inflammasomeindependent cytokine production upon these bacterial infections (Figure 3-5A, D, and E). IRF8 was constitutively expressed and its expression did not change significantly under our experimental conditions that promoted a variety of pro-inflammatory cytokines (Figure 3-3F). Further supporting our observations, silencing Irf8 in BMDMs resulted in decreased caspase-1 cleavage compared to that of control siRNA-treated BMDMs infected with $S$. Typhimurium, but not in those infected with $F$. novicida (Figure 3-6A, B). In addition, caspase-1 activation and cell death in $\operatorname{Irf} 8^{-/}$BMDMs infected with $S$. Typhimurium was less than that of $\operatorname{Irf} 8^{+/-}$BMDMs (Figure 3-6C, D). Altogether, our findings highlight the importance of IRF8 to enable recognition of bacterial components during infection for NLRC4 inflammasome activation.

\section{IRF8 Is Required for Expression of Murine Naips}

\section{Differential Expression of NLRC4 Inflammasome Components}

NAIPs belong to the NLR family of pattern recognition receptors (PRRs) and contain repeats of the inhibitor of apoptosis (IAP) domain also known as the Baculovirus inhibitor of apoptosis protein repeat (BIR) domain ${ }^{69}$. Association of each NAIP with its specific bacterial protein drives assembly and activation of the NLRC4 inflammasome. In mice, the corresponding NAIPs and ligands are NAIP1 for the T3SS needle, NAIP2 for the T3SS inner rod, and NAIP5 and NAIP6 for flagellin ${ }^{13}$. Humans encode a single NAIP that has the highest sequence homology with murine NAIP1 and appears to recognize needle, rod, and flagellin ${ }^{18-20}$. In our experiments with bacterial infection, we identified the requirement of IRF8 for optimal NLRC4 inflammasome activation (Figure 3-4). Following these observations, we performed microarray to examine possible

differential regulation of innate immune sensors in WT and $\operatorname{Irf} 8^{-/-}$BMDMs upon infection with $S$. Typhimurium. We found reduced expression of genes encoding for NAIP6, NAIP5, NAIP2, and NLRC4; all critical components of the NLRC4 
Figure 3-6. Absence of IRF8 attenuates NLRC4 activation

(A) Immunoblot analysis of caspase-1 in WT BMDMs transfected with a control siRNA or Irf8 siRNA and then infected with $S$. Typhimurium (MOI, 0.1) for $4 \mathrm{~h}$ or $F$. novicida (MOI, 100) for $20 \mathrm{~h} . \mathrm{Nlrc4}^{-/-}$(left) or $\mathrm{Aim}^{-/-}$(right) BMDMs were used as controls.

(B) Relative expression of the gene encoding IRF8 in WT BMDMs transfected with a control siRNA or Irf8 siRNA.

(C) Immunoblot analysis of caspase-1 in BMDMs that were infected with $S$.

Typhimurium (MOI, 0.1) and collected after $4 \mathrm{~h}$.

(D) Microscopic images of BMDMs that were infected with $S$. Typhimurium (MOI, 0.1).

(E) Immunoblot analysis of caspase-1 in BMDMs that were transfected with different doses of flagellin.

(F and $\mathrm{G}$ ) Release of IL-1 $\beta$ and $\mathrm{KC}$ in BMDMs treated with DOTAP, transfected with flagellin (DOTAP + Flgn), or treated with flagellin (Flgn).

(H and I) Immunoblot analysis of caspase-1 and assessment of IL-18 levels in BMDMs untreated or transfected with flagellin.

(J) Microscopic images of BMDMs transfected with PrgI (DOTAP + PrgI) or PrgJ (DOTAP + PrgJ).

Scale bars, $100 \mu \mathrm{m}$ (D and J), NS, not significant; $* \mathrm{P}<0.05, * * \mathrm{P}<0.01, * * * \mathrm{P}<0.001$ and $* * * * \mathrm{P}<0.0001$ (One-way ANOVA with Dunnett's multiple comparisons test). Data are from 3 (F and $\mathrm{G}$ ) or 2 (I) or representative of 2 (A-E, H, and J) independent experiments (mean $\pm \mathrm{SEM})$. 
A

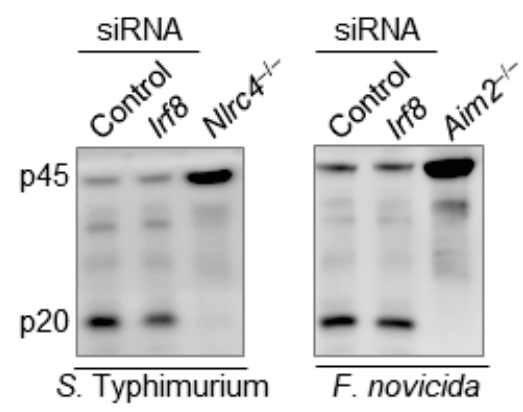

B

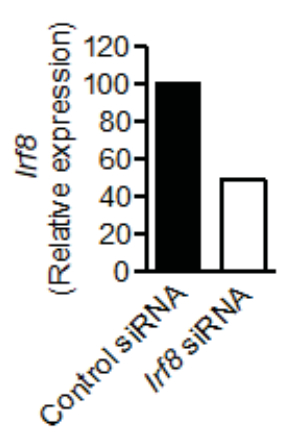

C

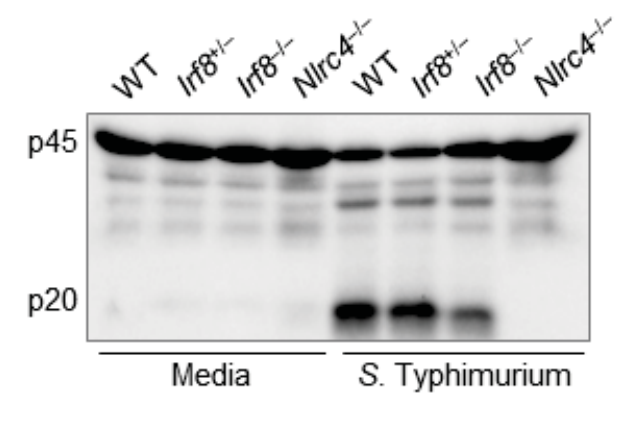

D

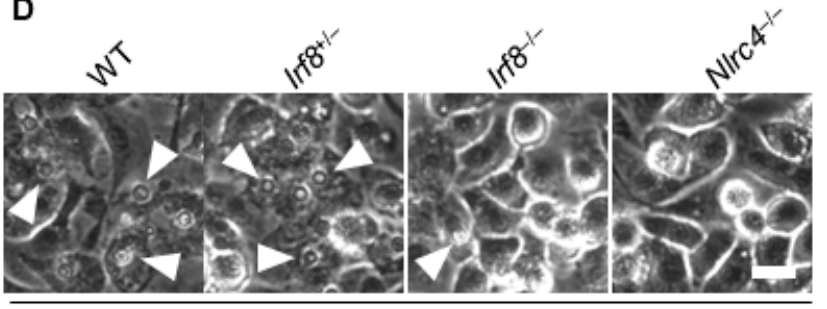

S. Typhimurium (0.1 moi)
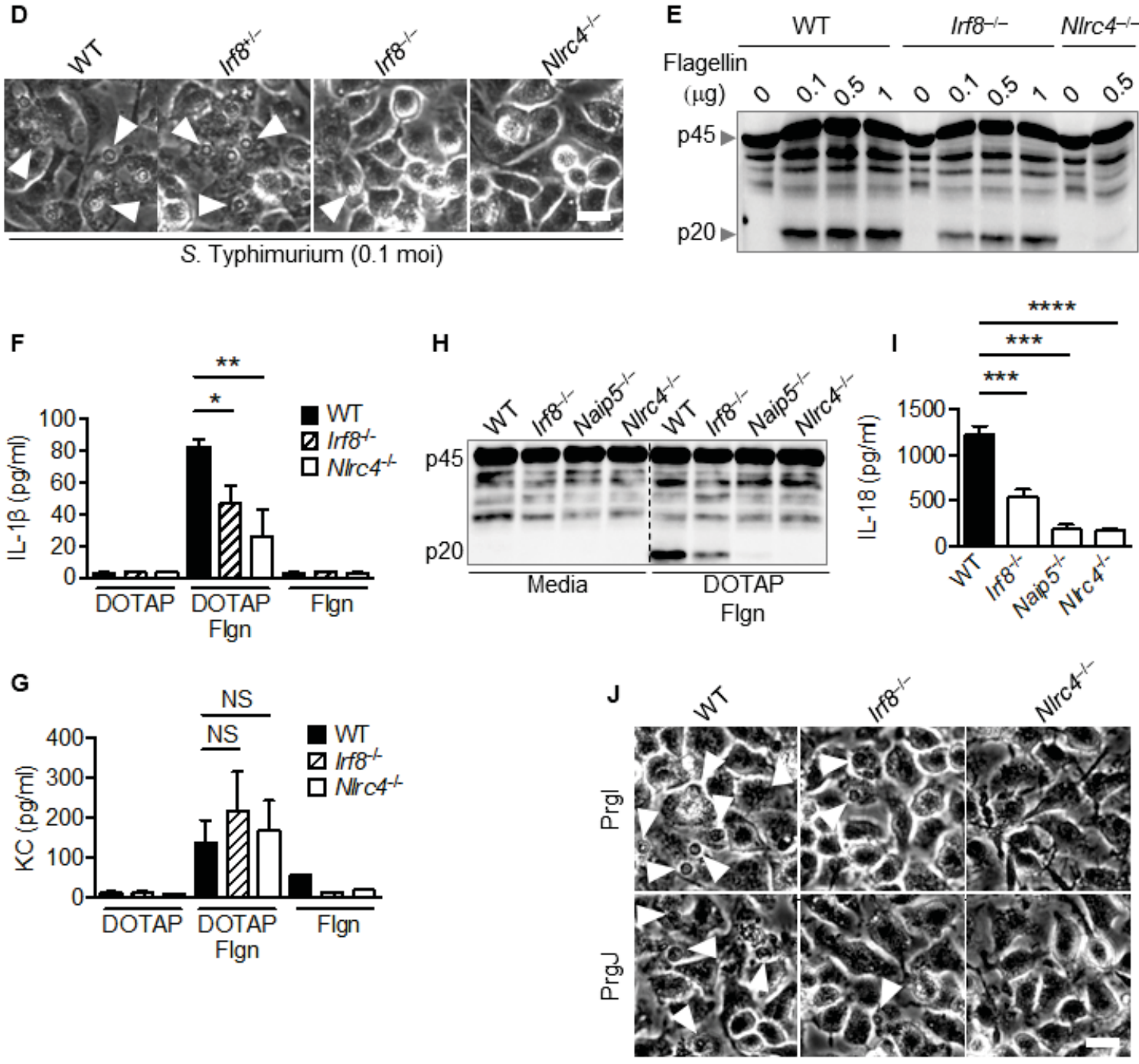
inflammasome complex (Figure 3-7A).

To find the regulatory interactions involving the NLRC4 inflammasome, we first generated a network of interactions between IRF8 and NAIPs (not shown) where IRF8 physically interacted with IRF4. Interestingly, IRF4 has the greatest sequence homology with IRF8 and requires SPI1 (also known as PU.1) as a binding partner to govern transcriptional programs in the B-cell lineage ${ }^{70}$. Our subsequent generation of an interaction network involving IRF4 and NAIPs revealed the co-expression between Irf8 and Spi1. Moreover, Irf8 was co-expressed with Naip2, Naip5, Naip6, and Nlrc4 but not with Naip1. The selected group of proteins exhibited clique-like properties, with each node being connected to most of the other nodes, suggesting a potential functional interaction (Figure 3-7B).

\section{Transcriptional Regulation of NLRC4 Inflammasome}

To address how NAIPs are being regulated by IRF8, we reanalyzed a published Chromatin immunoprecipitation-sequencing (ChIP-seq) dataset ${ }^{57}$. Sequences mapping to the promoter regions of Naip2, Naip5 and Naip6 were enriched, suggesting that their expression can be regulated by IRF8. We found no enrichment of sequences mapping to the Naipl promoter. Although we did not find enrichment in the promoter region of Nlrc4, we identified an IRF8 binding site in the intronic region. Transcription factor binding in the introns have previously been reported to regulate transcription of target genes ${ }^{71,72}$. IRF 8 binding in the intron might be regulating Nlrc4 expression by increasing chromatin accessibility for other transcription factors (Figure 3-7C). Real-time PCR (RT-PCR) analysis confirmed that Naip1, Naip2, Naip5, and Naip6 had reduced gene expression in response to $S$. Typhimurium in $\operatorname{Irf} 8^{-1-}$ BMDMs relative to WT BMDMs (Figure 3-7D). We also observed similar results when cells were transfected with flagellin (Figure 3-7E). Importantly, there was a basal defect in the transcription of all the Naips and Nlrc4, but not for the control gene Nlrp3 (Figure 3-7D, E, and F). Collectively, we show that IRF8 likely has binding sites in Naip promoters, contributing to the steady-state expression of Naips.

IFN signaling is important for the regulation of IRF8 ${ }^{29}$. Therefore, it might be possible that the molecules related to IFN production and signaling involve in the regulation of NAIPs. However we found similar gene expression of Naips and Nlrc4 in the BMDMs lacking IRF1, IRF3, IRF7, IRF3 and IRF7, IRF5, IRF9, IFNAR1, IFNAR2, STAT1, TRIF, MAVS, MDA5, cGAS, and STING, suggesting IRF8 specifically regulates Naips independent of IFN signaling (Figure 3-8). Our interaction map reveals a close network between IRF8, IRF4, and Ets family member SPI1 (Figure 3-7B). When we analyzed another published ChIP-seq dataset ${ }^{58}$, there was no enrichment of IRF4 binding to Naip2 or Naip5 promoters. (Figure 3-7G). In addition we checked for SPI1 binding sites ${ }^{36}$, where we found enrichment of SPI1 binding to Naip1, Naip2, Naip5, and Naip6 loci. This data suggests that SPI1 might work in conjunction with IRF8 for the transcriptional regulation of Naips (Figure 3-7H). 
Figure 3-7. IRF8 is a key factor in transcriptional regulation of Naips

(A) Microarray analysis of the expression of PRR-encoding genes $4 \mathrm{~h}$ after infection with $S$. Typhimurium (MOI, 0.1) in $\operatorname{Irf8^{-/}}$ BMDMs relative to that of WT.

(B) Interaction network visualizing the associations between IRF8, IRF4, SPI1, NLRC4, and NAIPs.

(C) Chromatin immunoprecipitation-sequencing (ChIP-seq) for IRF8 binding in Naipl, Naip2, Naip5, Naip6, and Nlrc4. Peaks indicate regions of DNA bound by IRF8.

(D) Real-time PCR (RT-PCR) analysis of genes encoding NAIPs in BMDMs before $(0 \mathrm{~h})$ and after $(1 \mathrm{~h}$ or $3 \mathrm{~h}$ ) infection with $S$. Typhimurium, normalized with the gene encoding HPRT.

(E) RT-PCR analysis of genes encoding NAIP5 and NAIP6 in BMDMs before ( $0 \mathrm{~h})$ and after $(1 \mathrm{~h}$ or $3 \mathrm{~h})$ transfection with $0.5 \mu \mathrm{g}$ flagellin, normalized with the gene encoding HPRT.

(F) RT-PCR analysis of genes encoding NLRP3 and NLRC4 in untreated BMDMs, normalized with the gene encoding HPRT.

(G) ChIP-seq for IRF4 binding in Naip2 and Naip5.

(H) ChIP-seq for SPI1 binding in Naip1, Naip2, Naip5, and Naip6, shown as MACS2 called peaks.

NS, not significant; and $* * \mathrm{P}<0.01$ (two-tailed t test). Data (D-F) are from 3 independent experiments (mean $\pm \mathrm{SEM})$. 
A

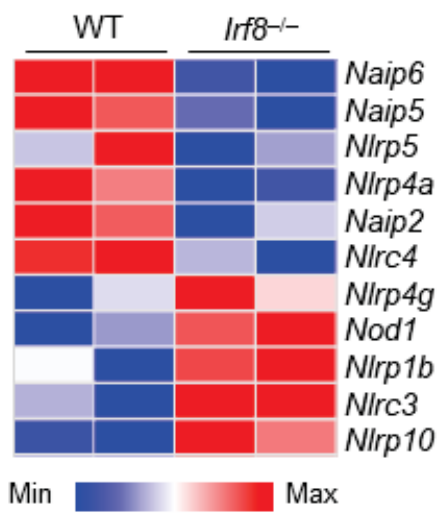

C
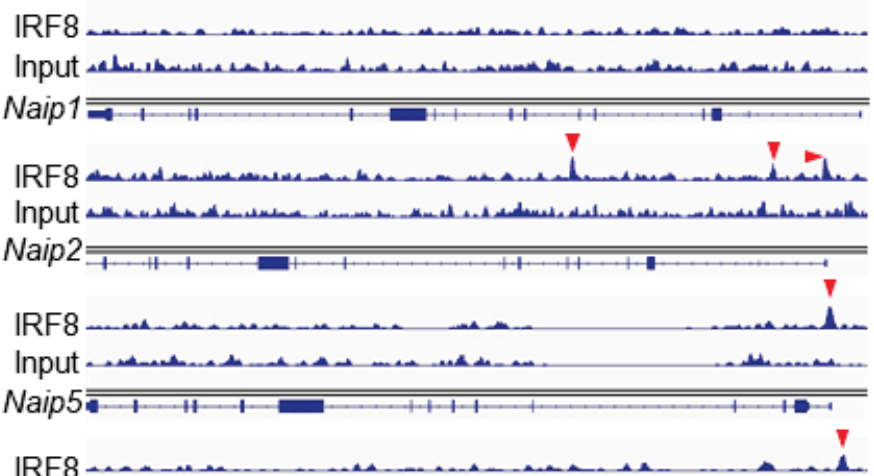

Input - ".

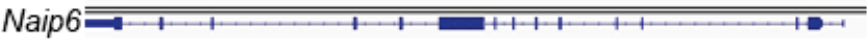

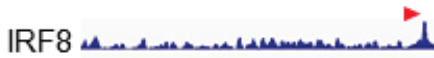

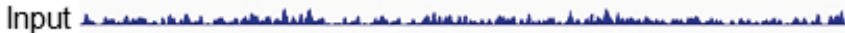

NIrC4

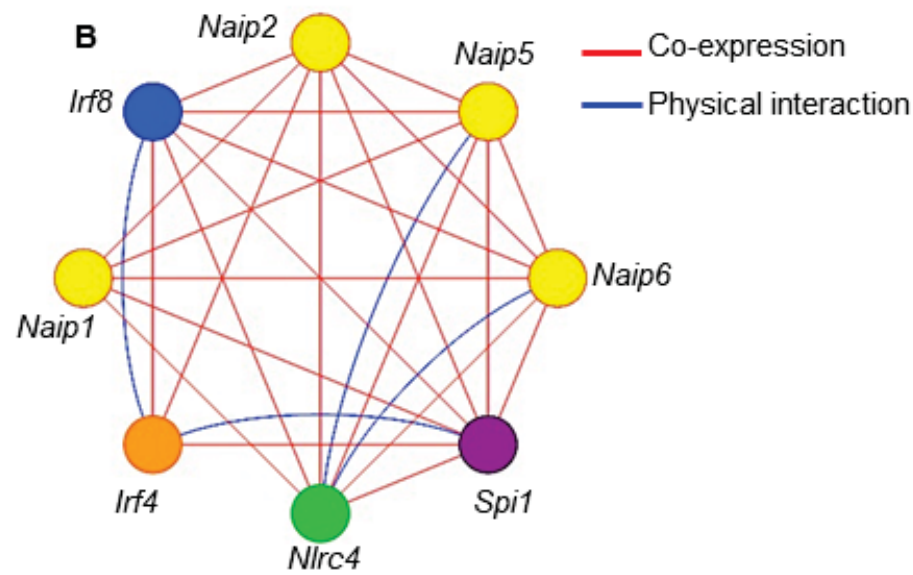

D Salmonella Typhimurium

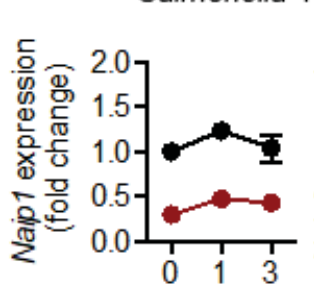

Time (h)

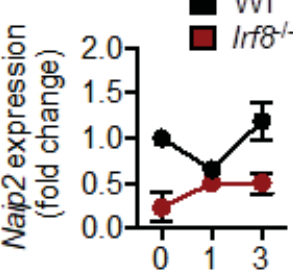

Time (h)

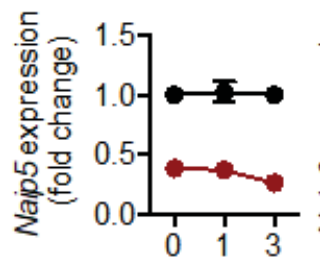

Time (h)

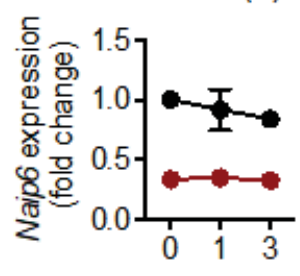

Time (h)
E

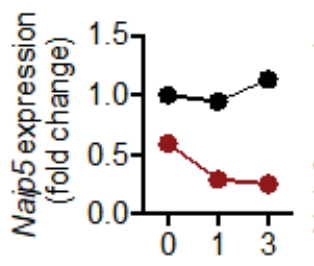

F

G

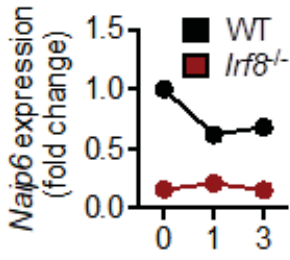

Flgn (h)

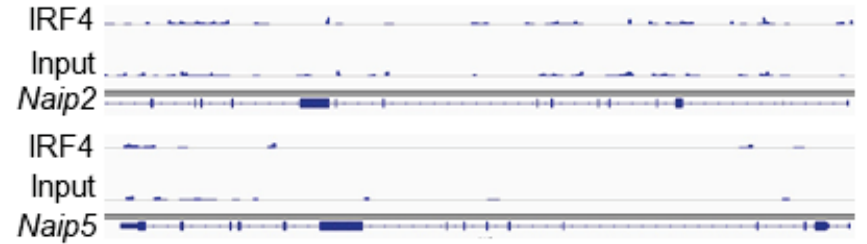

$\mathrm{H}$

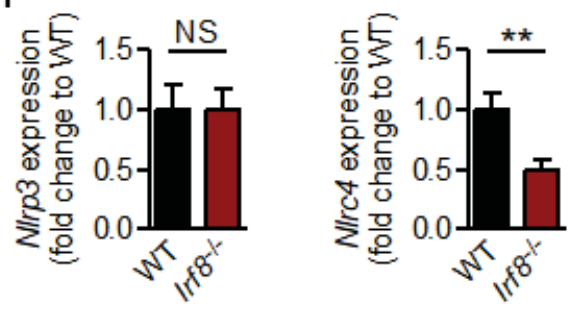

Naip1 

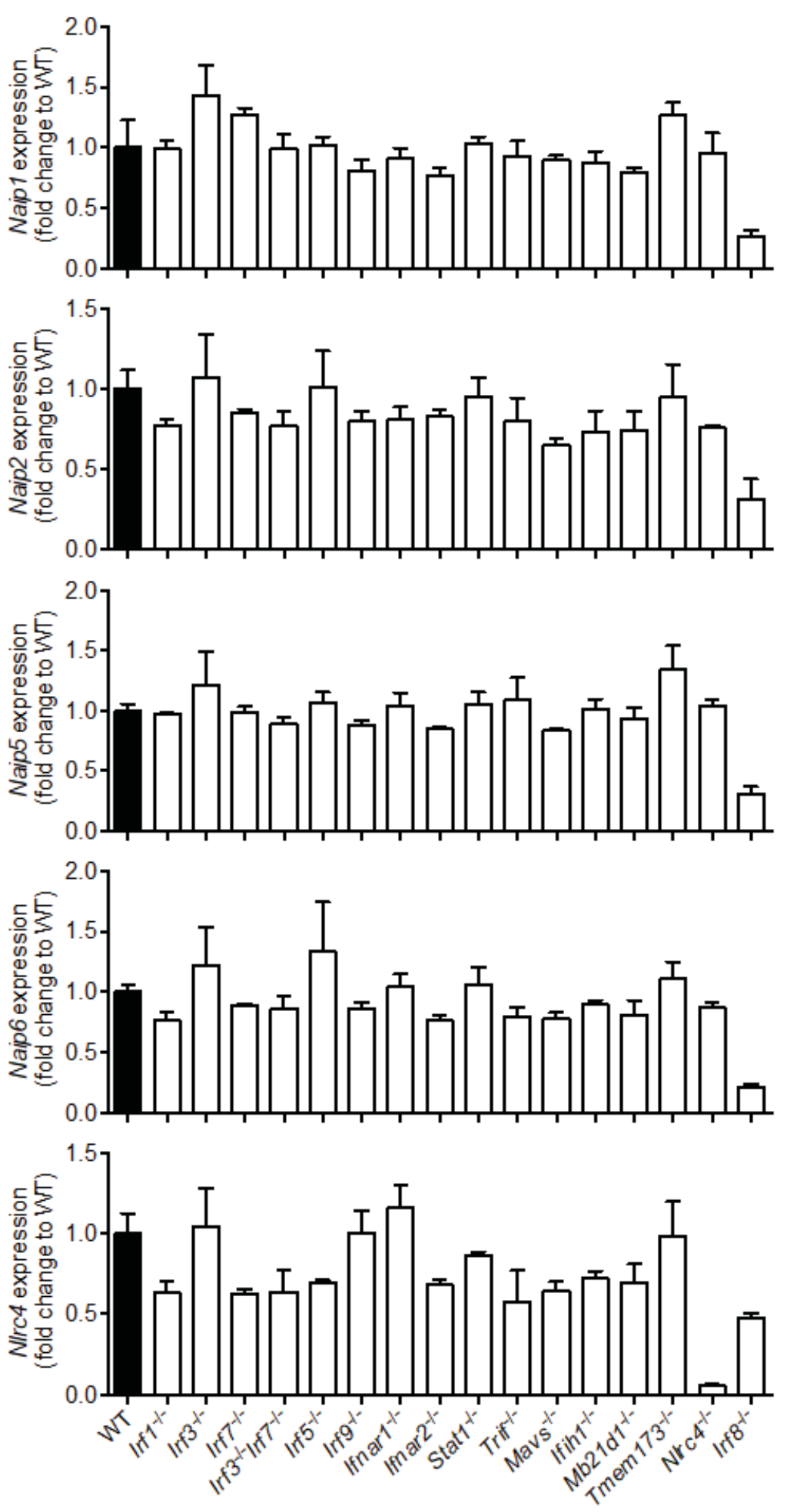

Figure 3-8. Gene expression of Naips is unaltered in BMDMs deficient in IFN pathway molecules

RT-PCR analysis of genes encoding NAIPs and NLRC4 in BMDMs, normalized with the gene encoding HPRT. Data are from 2 independent experiments (mean $\pm \mathrm{SEM}$ ). 
To validate IRF8 binding to Naip promoters found in the public ChIP analysis, we designed primer sets specific to the IRF8 consensus sequence at -590 and -390 on the promoter regions of Naip 2 and Naip 5, respectively, to perform targeted ChIP-PCR. The samples immunoprecipitated with IRF8 antibody but not the control IgG antibody yielded amplified PCR products, suggesting the recruitment of IRF8 onto the Naip2 and Naip5 promoters (Figure 3-9A). Next, to gain further insight into the molecular mechanism of IRF8-mediated transcription of Naips, we cloned the promoters of Naip2 or Naip5 into a luciferase reporter vector. Luciferase expression was significantly upregulated in cells that were co-transfected with Irf8 compared to those transfected with empty vectors, which suggested that IRF8 regulates mRNA abundance of Naip2 and Naip5 at the level of transcription (Figure 3-9B). Furthermore we sought to confirm the direct recruitment of IRF8 to Naip promoters. To this end, we performed electrophoretic mobility shift assay (EMSA) where we observed IRF8 binding to Naip2 and Naip5 promoters in nuclear extracts from WT BMDMs (Figure 3-9C). To determine whether the binding was specific to IRF8, we utilized competitive EMSA and antibody-mediated super shift assays. Non-labeled Naip2 or Naip5 oligonucleotides successfully competed with the labeled probes and addition of IRF8 antibody abolished the migration of the IRF8-Naip promoter complex into the membrane (Figure 3-9C). Together, these results establish that IRF8 directly binds to the promoters of Naip2 and Naip5 to regulate their expression. To further corroborate these findings, we reconstituted IRF8 in $\operatorname{Irf} 8^{-/-}$BMDMs. Compared to untreated or control-transfected cells, reconstitution of IRF8 increased the expression of Naip1, Naip2, Naip5, and Naip6. (Figure 3-9D). All these findings mechanistically prove that IRF8 regulates Naips at the transcriptional level.

\section{Functional Regulation of Individual NAIPs}

Furthermore, we examined the role of IRF8 in NLRC4 inflammasome activation in response to bacterial flagellin and components of the T3SS apparatus. Flagellin treatment alone without the transfection agent DOTAP failed to induce processing of caspase-1. Intracellular delivery of flagellin led to caspase-1 activation in WT BMDMs but activation was greatly impaired in $\operatorname{Irf8^{-/}}$ BMDMs (Figure 3-10A and Figure 3-6E). In line with these observations, inflammasome-dependent cytokines IL-18 and IL-1 $\beta$ were reduced whereas $\mathrm{KC}$ was unaffected by the absence of IRF8 (Figure 3-10B and Figure 3-6F, G). Correspondingly, BMDMs lacking IRF8 were compromised in their ability to undergo pyroptosis after flagellin transfection (Figure 3-10C, D). Because NAIP5 is the receptor for cytosolic flagellin recognition, we checked for inflammasome activation in Naip $5^{-/}$BMDMs transfected with flagellin. As expected, caspase-1 maturation and IL-18 production were diminished in cells lacking NAIP5 to a similar extent as seen in cells lacking NLRC4 (Figure 3-6H, I). Irf $8^{-1-}$ BMDMs also had decreased inflammasome activity in response to bacterial T3SS. Transfection of the needle protein PrgI or the rod protein PrgJ into $\operatorname{Irf} 8^{-/-}$BMDMs resulted in reduced caspase-1 activation, IL-18 release, and cell death compared to that of WT (Figure 3-10E through $\mathbf{J}$ and Figure 3-6J). These results demonstrate the significance of IRF8 for sterile NLRC4 inflammasome activation triggered by pure ligands of NAIPs. 
A

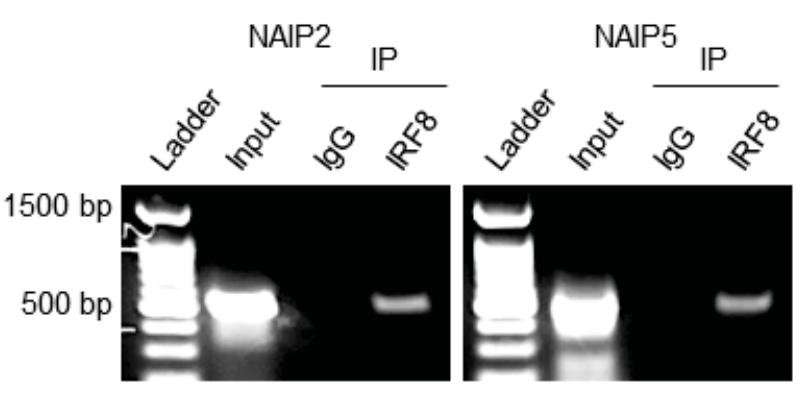

C

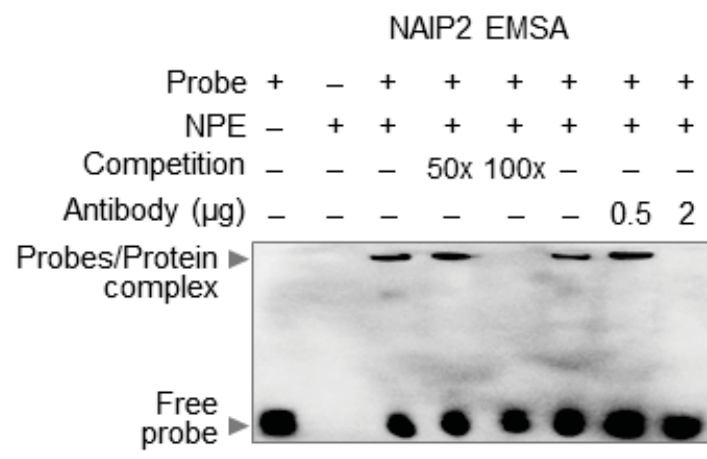

B

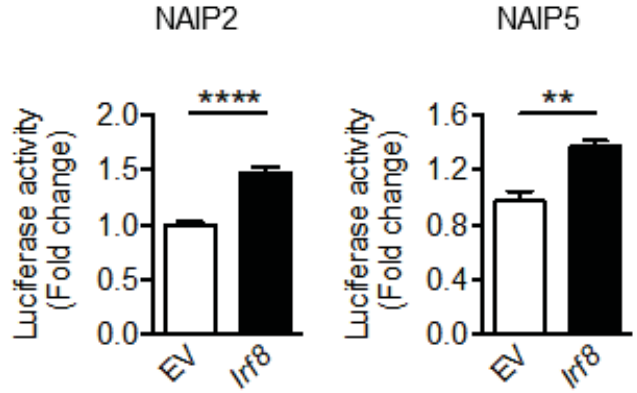

D
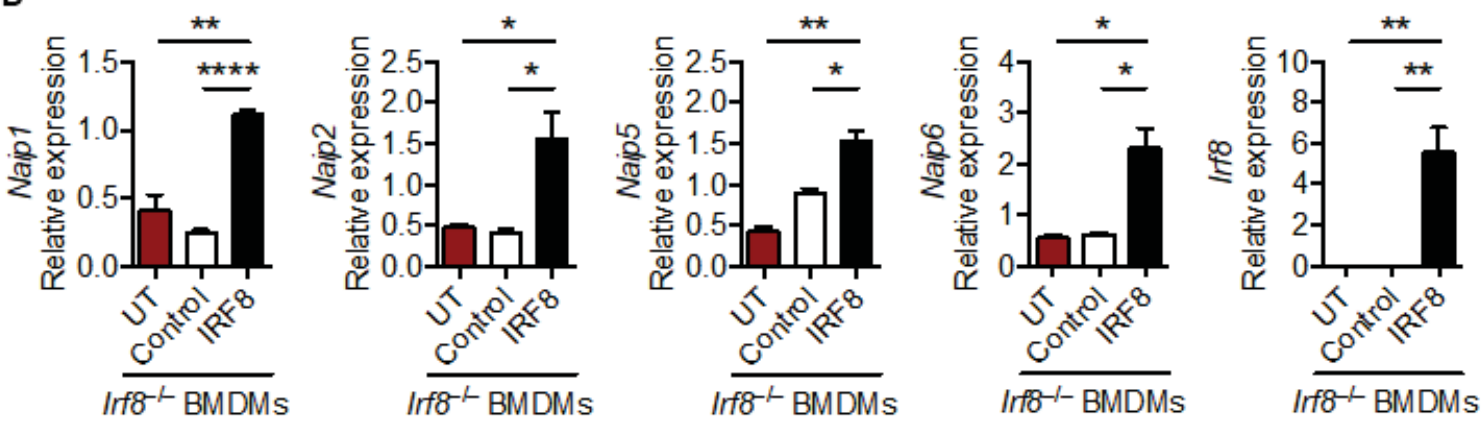

Figure 3-9. Transcriptional activity of IRF8 for Naips

(A) ChIP for IRF8 followed by semi-quantitative PCR for Naip2 or Naip5 promoters were performed in BMDMs.

(B) Relative reporter luciferase activity for Naip2 or Naip5 promoters in IRF8 overexpressing cells, presented as fold change with respect to empty vector (EV) transfected cells. Data was normalized for transfection efficiency by normalizing firefly luciferase activity with renilla luciferase activity.

(C) Electrophoretic mobility shift assay (EMSA) was performed with Naip2 or Naip5 oligonucleotide probes incubated with nuclear protein extracts (NPE) from BMDMs. (D) RT-PCR analysis of Naip1, Naip2, Naip5, Naip6, and Irf8 in Irf8 ${ }^{-1-}$ BMDMs transfected with control or Irf8 vectors, normalized to levels of Gapdh. NS, not significant; $* \mathrm{P}<0.05, * * \mathrm{P}<0.01$, and $* * * * \mathrm{P}<0.0001$ (two-tailed t test). Data are representative of 2 (A and $\mathrm{C}$ ) or from 2 (B and D) independent experiments (mean \pm SEM). 
Figure 3-10. NLRC4 inflammasome activation in response to isolated bacterial proteins is impaired in the absence of IRF8

(A-D) BMDMs were treated with the liposomal agent DOTAP alone, transfected with $0.5 \mu \mathrm{g}$ flagellin (DOTAP + Flgn), or treated with $0.5 \mu \mathrm{g}$ flagellin (Flgn) alone.

(A) Immunoblot analysis of caspase-1.

(B) Assessment of IL-18 levels in cell supernatants.

(C) Microscopic analysis of cell death.

(D) Cell death was assessed by evaluating the release of LDH.

(E-G) Immunoblot analysis of caspase-1, IL-18 release, and cell death in BMDMs transfected with PrgI (DOTAP + PrgI) or treated with PrgI alone. (H-J) Immunoblot analysis of caspase-1, IL-18 release, and cell death in BMDMs transfected with PrgJ (DOTAP + PrgJ) or treated with PrgJ alone.

Scale bars, $100 \mu \mathrm{m}(\mathrm{C})$, NS, not significant; $* \mathrm{P}<0.05$, $* * \mathrm{P}<0.01$ and $* * * \mathrm{P}<0.001$

(One-way ANOVA with Dunnett's multiple comparisons test). Data are representative of 3 (A and C) or 2 (E and H) or from 3 (B and D) or 2 (F, G, I, and J) independent experiments (mean $\pm \mathrm{SEM}$ ). 
A

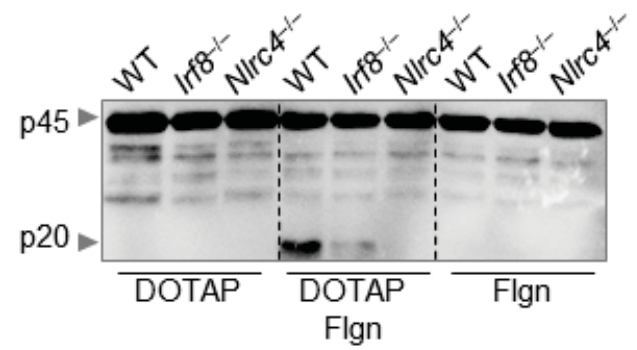

C

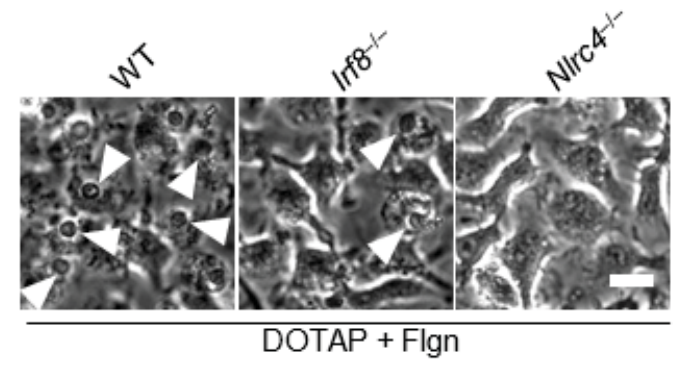

E

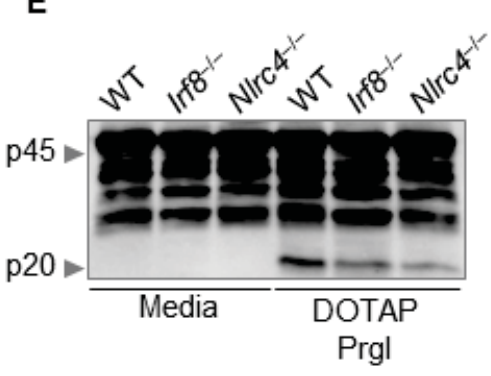

H

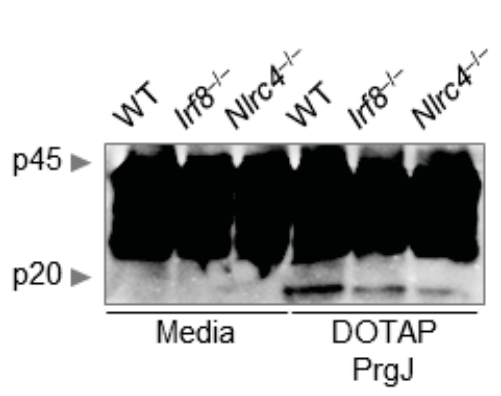

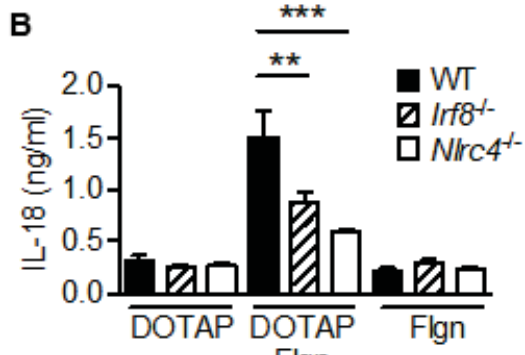

D
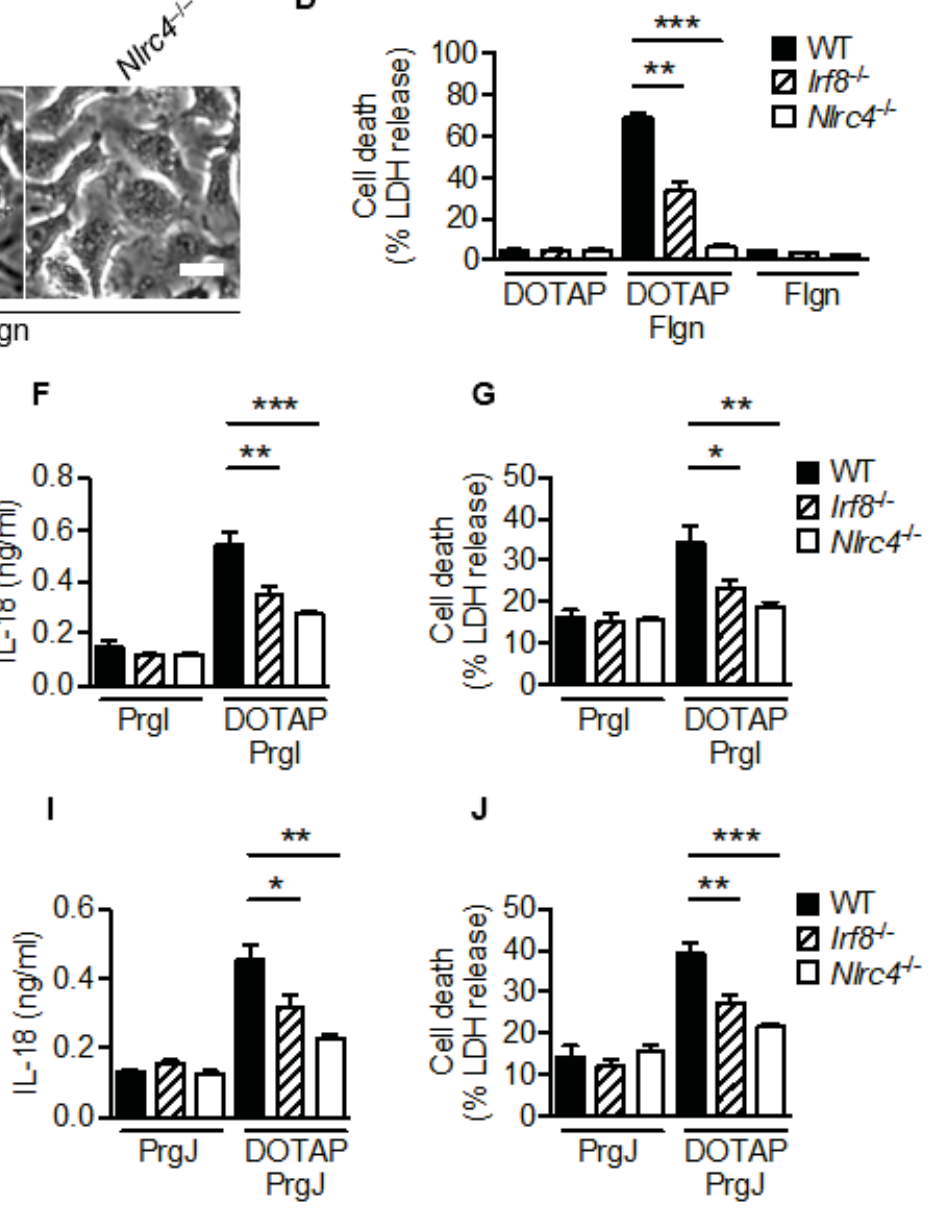


\section{IRF8 Protects Against S. Typhimurium and B. thailandensis Infection In Vivo}

\section{Susceptibility to In Vivo Infection}

NLRC4 inflammasome activation is required for bacterial clearance in $S$. Typhimurium infected mice ${ }^{73}$. To examine the in vivo relevance of IRF8 we infected mice intraperitoneally with $S$. Typhimurium and monitored body weight change and mortality during the course of infection. Compared to WT mice, Irf $8^{-1-}$ mice exhibited rapid weight loss between day 1 and day 2 which was similar to the degree of wasting in $\mathrm{Nlrc}^{-/-}$mice. On the other hand $\operatorname{Irf} 8^{+/-}$mice followed the trend of WT mice, showing a gradual decrease in body weight and successive recovery (Figure 3-11A). All $\operatorname{Irf} 8^{-1-}$ mice succumbed to infection within 4 days, while during the same time $100 \%$ of the $\operatorname{Irf} 8^{+/-}$and WT mice were still alive. We continued monitoring until day 12 in which the accumulated mortality of $\operatorname{Irf} 8^{+/-}$and WT mice was about $50 \%$. The high susceptibility of Nlrc $4^{-1-}$ mice, as reported ${ }^{73}$, was comparable to that of $\mathrm{Irf}^{-1-}$ mice (Figure 3-11B). The accelerated mortality of mice lacking IRF8 or NLRC4 highlights the importance of early innate immune responses to contain the pathogen which in turn greatly affects the outcome of the infection. Moreover, $\operatorname{Irf} 8^{-/-}$mice were more susceptible to $B$. thailandensis infection. Within 4 days all $\operatorname{Irf} 8^{-1-}$ mice died, but more than $50 \%$ of WT mice survived (Figure 3-12A). Interestingly, Naip $^{-1-}$ mice were more susceptible to $S$. Typhimurium infection than WT mice but still more resistant than $\mathrm{Irf}^{-/-}$or $N l r c 4^{-1-}$ mice (Figure 3-11B). This intermediate phenotype suggests that other NAIPs also contribute to mount NLRC4 inflammasome activation in response to $S$. Typhimurium infection in vivo.

The bacterial burden in the spleen and liver of $\operatorname{Irf8^{-/-}}$ or $N l r c 4^{-1-}$ mice was greater than that of WT mice upon $S$. Typhimurium infection (Figure 3-11C, D). Similarly, Irf $8^{-}$ ${ }^{1-}$ mice had increased bacterial burden in the lung, liver, and spleen after B. thailandensis infection compared to WT mice (Figure 3-12B). IL-18 levels in the spleen, liver, and serum of these mice were also assessed 3 days after $S$. Typhimurium infection, or 2 days after $B$. thailandensis infection. Less IL-18 was detected in the tissues and serum of Irf $8^{-}$ ${ }^{1-}$ mice than in those of WT, reflecting defective inflammasome activation in response to infection in $\operatorname{Irf} 8^{-/-}$mice (Figure 3-11E, F and Figure 3-12C). Furthermore, we investigated the numbers of circulating blood cells from the peripheral blood of infected WT and $\operatorname{Irf8^{-/-}}$ mice using an automated hematology analyzer. Relative to WT mice, Irf $8^{-}$ ${ }^{-}$mice exhibited higher numbers of total white blood cells (WBCs), neutrophils, and lymphocytes 3 days after $S$. Typhimurium infection, whereas no significant differences were noted in the numbers of other cell types (Figure 3-13A). Similarly, we found more circulating WBCs and neutrophils in $\operatorname{Irf} 8^{--}$mice 2 days after $B$. thailandensis infection, suggesting that the susceptibility of IRF8-deficient mice to infection was not due to impaired immune cell production and circulation (Figure 3-13B). However, we observed more prominent recruitment of immune cells, which were largely composed of neutrophils, in the lungs of $B$. thailandensis-infected WT mice than in the lungs of $\operatorname{Irf8^{-/-}}$ mice (Figure 3-12D). This may be due to the decreased production of inflammasomedependent cytokines in IRF8-deficient mice. 
Figure 3-11. IRF8 confers protection against $\boldsymbol{S}$. Typhimurium in vivo

(A) Body weight of 8-week-old WT $(\mathrm{n}=13), \operatorname{Irf}^{-/-}(\mathrm{n}=7), \operatorname{Irf}^{+/-}(\mathrm{n}=6)$ and $\operatorname{Nlrc}^{-1-}(\mathrm{n}=9)$ mice infected intraperitoneally with $10^{3}$ colony forming units (CFU) of $S$. Typhimurium. (B) Survival of WT $(\mathrm{n}=13), \operatorname{Irf8}^{-/-}(\mathrm{n}=7), \operatorname{Irf}^{+/-}(\mathrm{n}=6), \operatorname{Naip}^{-/-}(\mathrm{n}=9)$, and $\operatorname{NlrC}^{-/-}(\mathrm{n}=9)$ mice infected as (A).

(C and D) Bacterial burden in the spleen and liver of WT $(\mathrm{n}=20), \operatorname{Irf} 8^{-/-}(\mathrm{n}=15), N \operatorname{lrc} 4^{-/-}$ $(\mathrm{n}=15)$ and $\operatorname{Naip5}^{-1-}(\mathrm{n}=9)$ mice on day 3 after infection as $(\mathrm{A})$.

(E and F) Analysis of IL-18 in the spleen and liver collected from WT ( $\mathrm{n}=10), \operatorname{Irf} 8^{-1-}$ $(\mathrm{n}=6), \operatorname{Nlrc}^{-/-}(\mathrm{n}=10)$ and Naip5 ${ }^{-/-}(\mathrm{n}=6)$ mice on day 3 after infection as (A).

(G-L) RT-PCR analysis of genes encoding NAIPs, NLRC4, and IRF8 in the spleen collected from WT and $\operatorname{Irf} 8^{-/-}$mice before infection (day 0) and after infection (day 3 ) as (A), normalized with the gene encoding HPRT.

NS, not significant; $* \mathrm{P}<0.05, * * * \mathrm{P}<0.0001$ and $* * * * \mathrm{P}<0.0001$ (log-rank test [B], ANOVA with Dunn's multiple comparisons test [C-F], or Two-way ANOVA with Tukey's multiple comparisons test $[\mathrm{G}-\mathrm{L}]$ ). Data are from 2 experiments. 

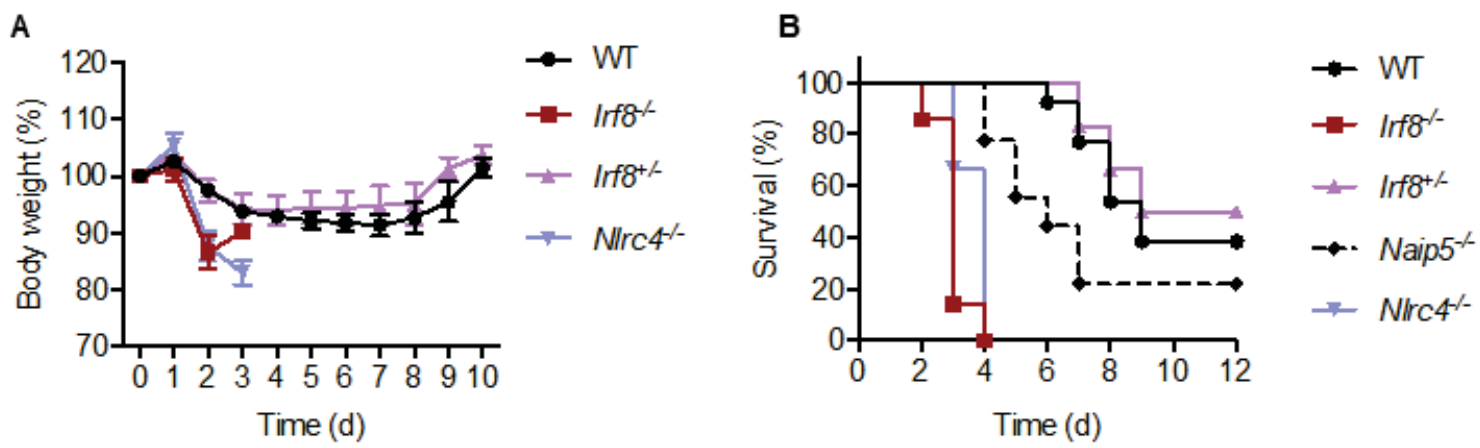

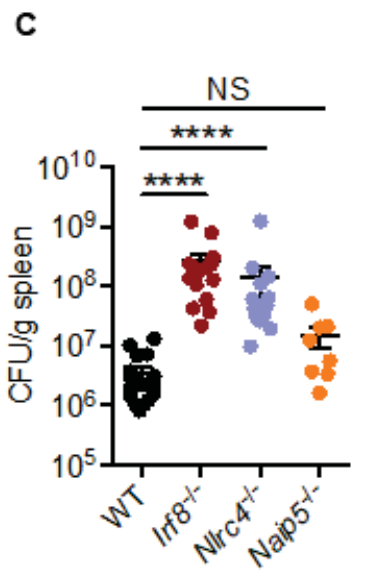

G

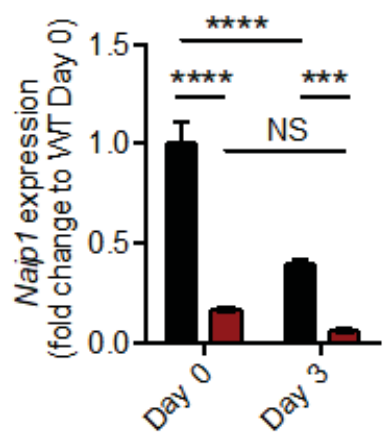

J

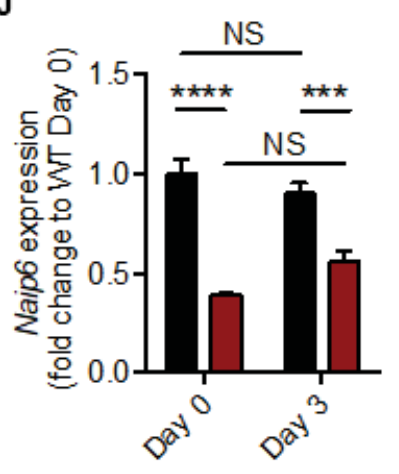

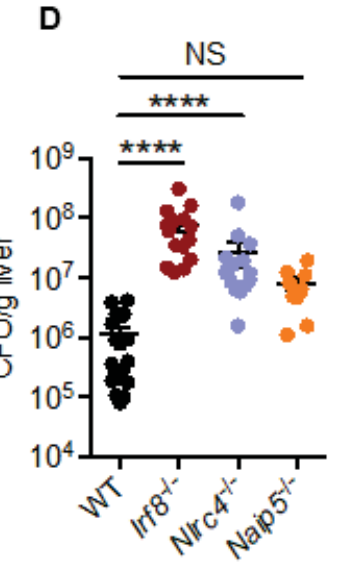

H

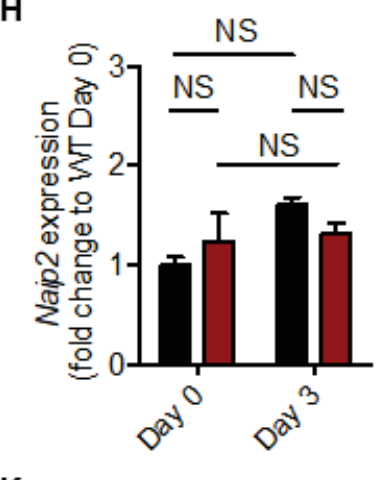

K

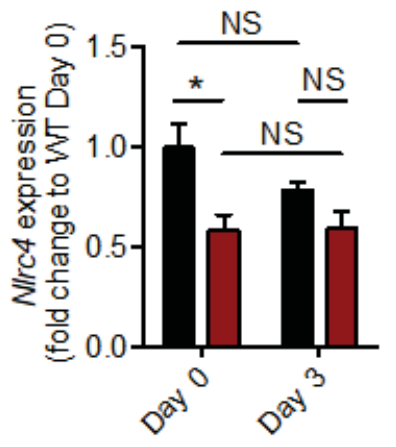

F

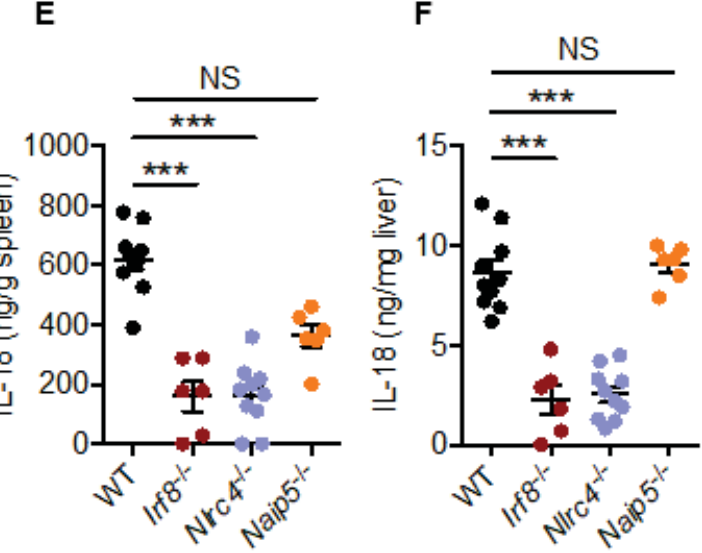


Figure 3-12. IRF8 confers protection against $B$. thailandensis in vivo

(A) Survival of 8-week-old WT $(\mathrm{n}=11)$ and $\operatorname{Irf8^{-/-}}(\mathrm{n}=7)$ mice infected intranasally with 5 $\times 10^{4} \mathrm{CFU}$ of $B$. thailandensis.

(B) Bacterial burden in the lungs, liver and spleen of WT $(n=10)$ and $\operatorname{Irf} 8^{-/-}(\mathrm{n}=9)$ mice on day 2 after infection as (A).

(C) Analysis of IL-18 in the lungs, liver, spleen, and serum collected from WT $(n=10)$ and $\operatorname{Irf} 8^{--}(\mathrm{n}=9)$ mice on day 2 after infection as (A).

(D) H\&E staining of lungs collected from WT and $\operatorname{Irf8^{-/-}}$ mice on day 2 after infection as (A).

(E-H) RT-PCR analysis of genes encoding NAIPs and NLRC4 in spleen and lungs collected from WT $(\mathrm{n}=10)$ and $\operatorname{Irf} 8^{-/-}(\mathrm{n}=9)$ mice before (day 0$)$ and after infection (day 2) as (A), normalized with the gene encoding HPRT.

Scale bars, $250 \mu \mathrm{m}$ (D), NS, not significant; $* \mathrm{P}<0.05, * * \mathrm{P}<0.001, * * * \mathrm{P}<0.0001$ and $* * * * \mathrm{P}<0.0001$ (log-rank test [A] or two-tailed t test [B and C] or Two-way ANOVA with Tukey's multiple comparisons test $[\mathrm{E}-\mathrm{H}])$. Data are representative of 2 (D) or from $2(\mathrm{~A}-\mathrm{C}$ and $\mathrm{E}-\mathrm{H})$ independent experiments. 

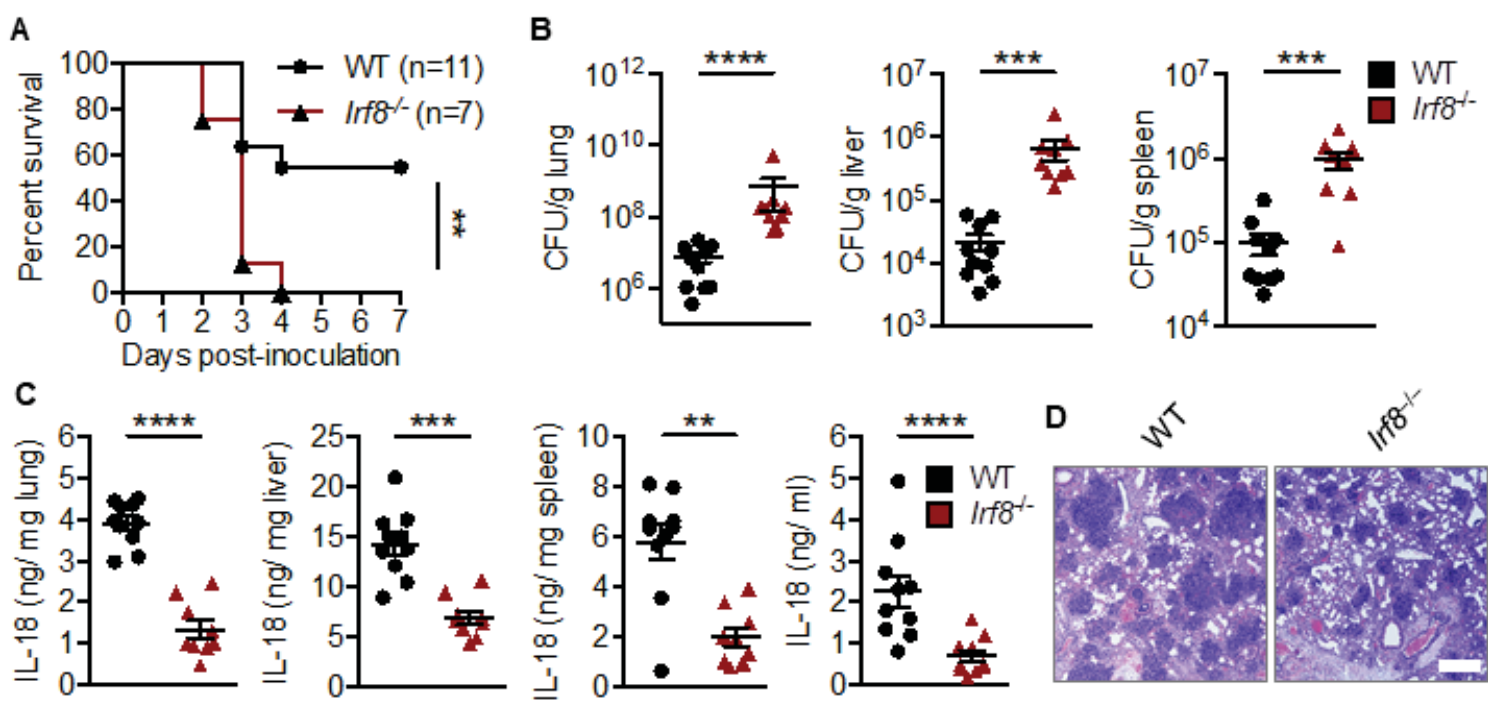

\section{E Spleen}

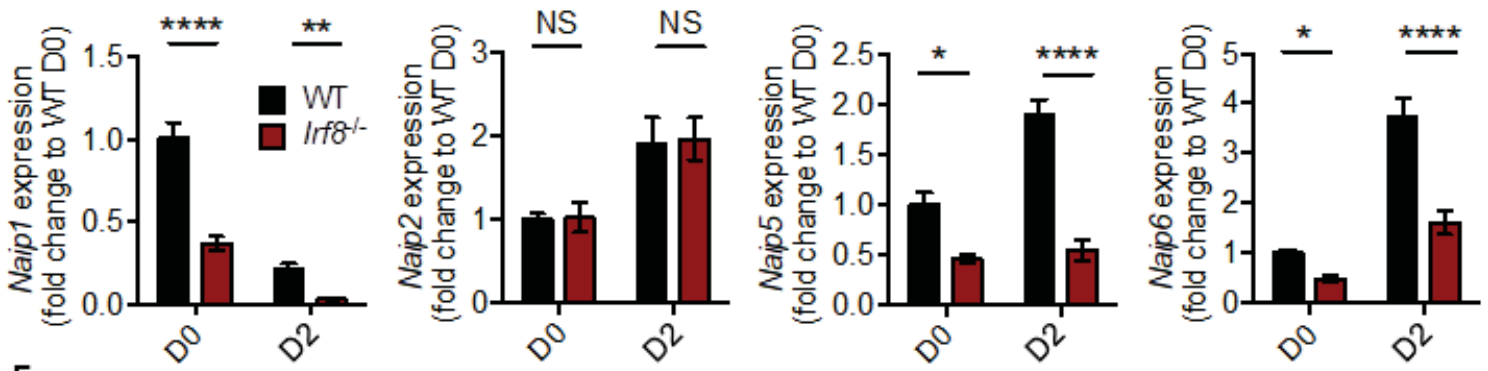

F Lungs

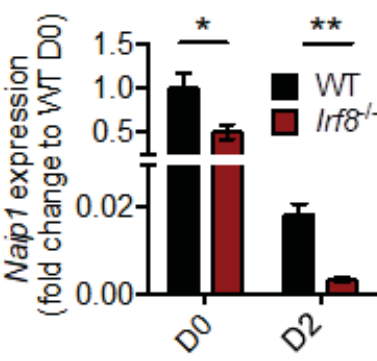

G Spleen

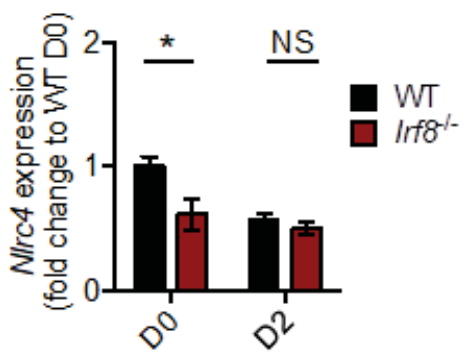

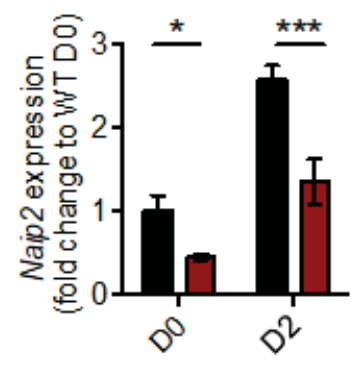

H Lungs
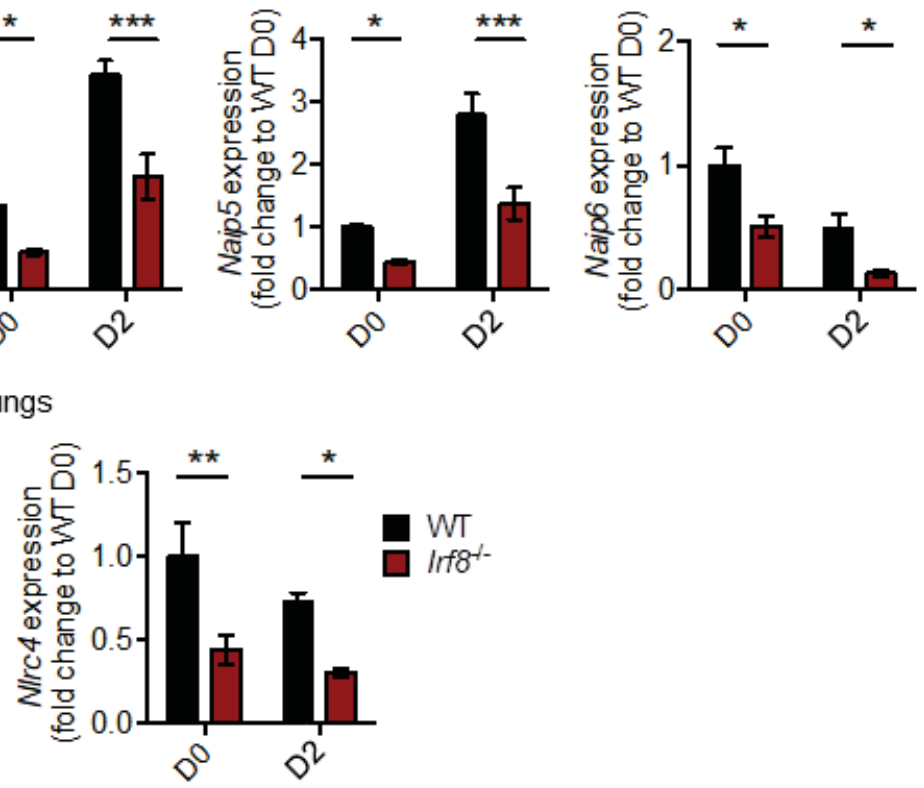
Figure 3-13. IRF8-deficient mice have sufficient numbers of circulatory immune cells following infection

(A) Blood cell counts from peripheral blood of WT $(\mathrm{n}=10), \operatorname{Irf} 8^{-/-}(\mathrm{n}=6)$, and $\mathrm{Nlrc}^{-1-}$ $(\mathrm{n}=10)$ mice on day 3 after intraperitoneal infection with $10^{3} \mathrm{CFU}$ of $S$. Typhimurium. (B) Blood cell counts from peripheral blood of WT $(\mathrm{n}=10)$ and $\operatorname{Irf} 8^{-/}(\mathrm{n}=9)$ mice on day 2 after intranasal infection with $5 \times 10^{4} \mathrm{CFU}$ of $B$. thailandensis.

NS, not significant; $* \mathrm{P}<0.05,{ }^{*} * \mathrm{P}<0.01$ and $* * * \mathrm{P}<0.001$ (One-way ANOVA with Dunnett's multiple comparisons test [A] or two-tailed t test [B]). Data are from 1 independent experiment. 

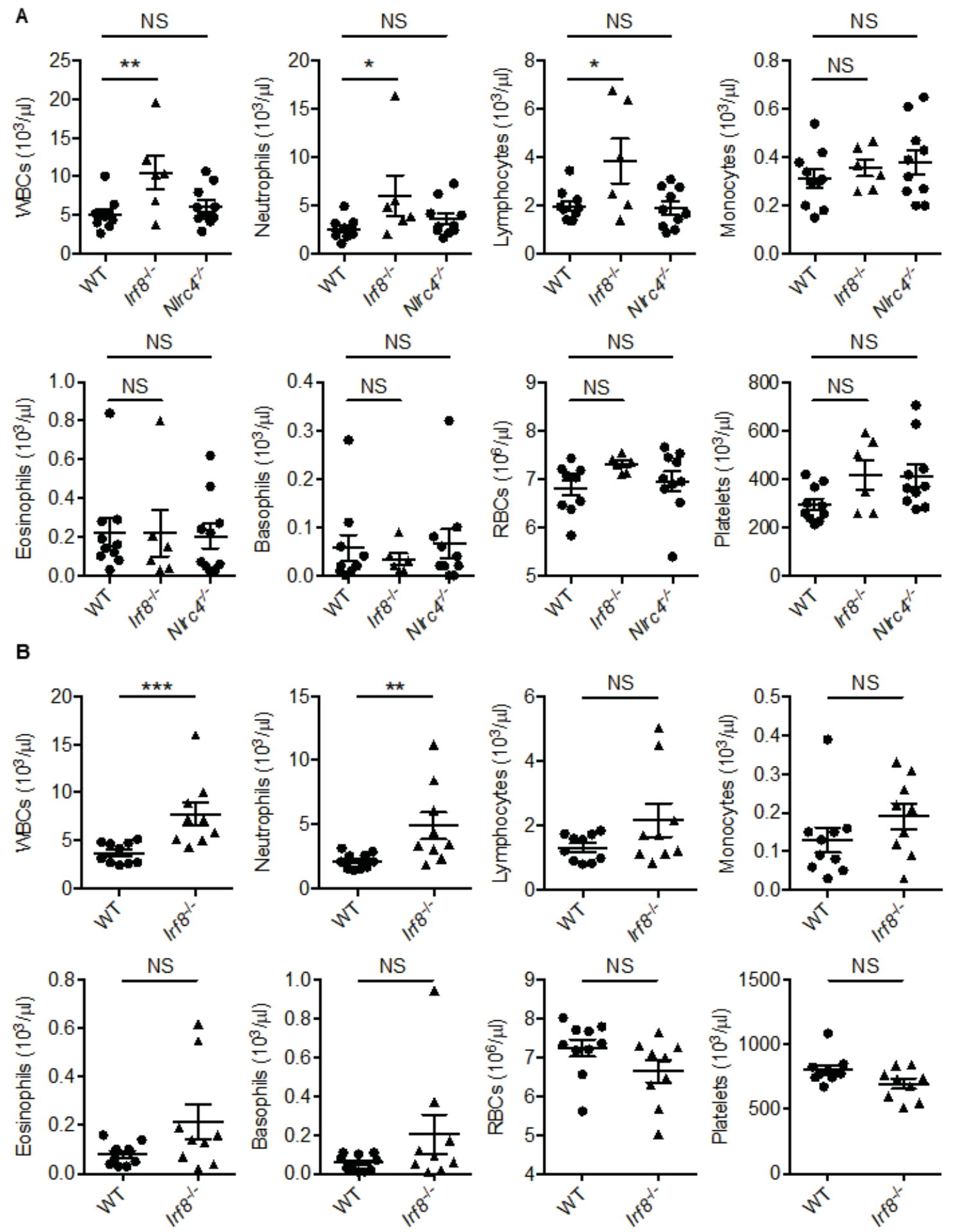
The main effectors of inflammasome activation are the cytokines IL-1 $\beta$ and IL-18, and the recently identified pore-forming molecule gasdermin $\mathrm{D}^{2-4}$. We used the above $S$. Typhimurium infection model to further access the relative contribution of cytokine

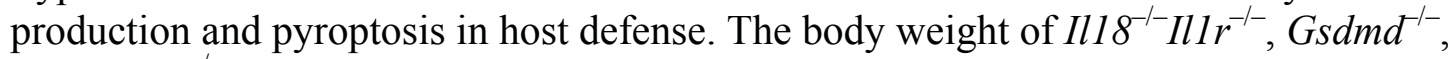

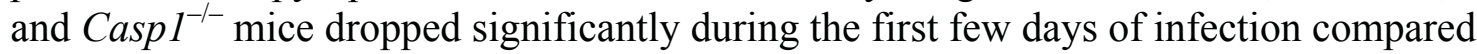
to WT mice (Figure 3-14A). In 4 days, all mice from the three knock-out genotypes succumbed to infection, without showing any significant difference between the groups (Figure 3-14B). In comparison to WT mice, the bacterial loads of $G s d m d^{-1-}$ mice and $I l 18^{-/} I l 1 r^{-1-}$ mice were greater, supporting the idea that inflammasome-dependent cytokines and cell death were both critical in mediating host defense against $S$. Typhimurium infection (Figure 3-14C).

\section{Tissue Expression of Naips}

Finally, we examined Naip gene expression patterns in the spleen of WT and Irf8 ${ }^{1-}$ mice before and after infection with $S$. Typhimurium. $\operatorname{Irf} 8^{-/-}$mice had basally lower expression of Naip1, Naip5, Naip6, Nlrc4, but not Naip2 than WT mice (Figure 3-11G through K). After infection, Naipl and Naip6 gene expression remained lower in Irf $8^{-/-}$ mice compared to that of WT mice (Figure 3-11G, J). In WT mice we observed significant reduction in the gene expression of Naipl and Naip5 after infection, which might be due to reduction in the levels of $\operatorname{Irf8}$ (Figure 3-11G, I, and L). Similarly, we observed lower gene expression of Naip 1, Naip5, and Naip6 in the spleen of $\operatorname{Irf8^{-1-}}$ mice compared to those of WT mice after B. thailandensis infection (Figure 3-12E, G). However, in the lungs we observed decreased expression of Naip2 along with other Naips and Nlrc 4 before and after B. thailandensis infection (Figure 3-12F, H). Thus, in the absence of IRF8, infected mice were not able to promote sufficient inflammasome activation due to the lack of Naips expression. These data display an important role for IRF8 in regulating the NLRC4-dependent clearance of $S$. Typhimurium and $B$. thailandensis. 
A

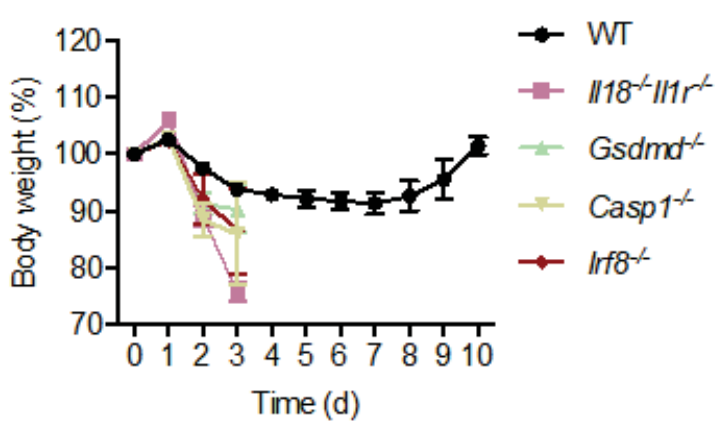

B

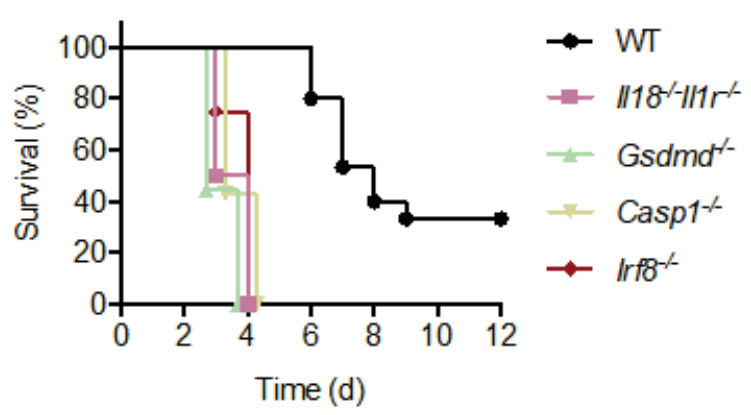

C
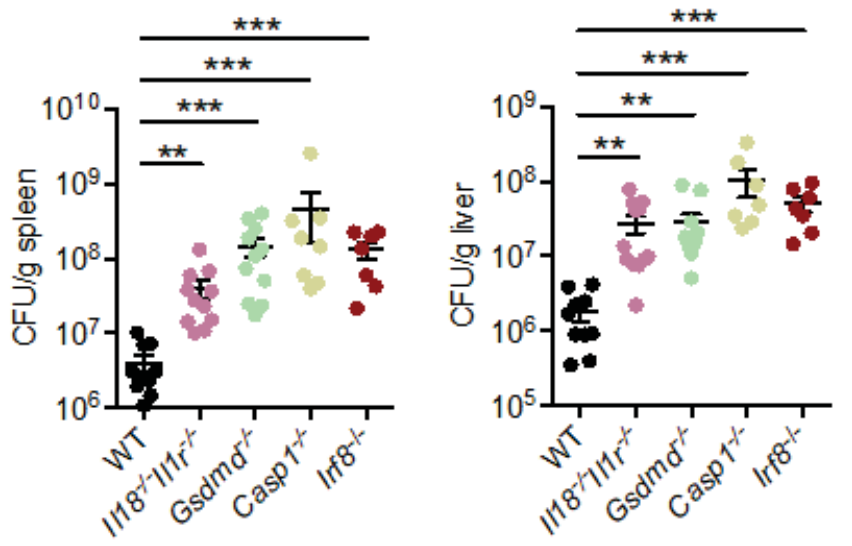

Figure 3-14. Inflammasome-dependent cytokines and pyroptosis both contribute to protection against $S$. Typhimurium infection in vivo

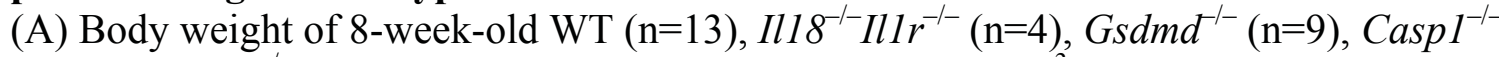
$(\mathrm{n}=7)$, and $\operatorname{Irf} 8^{-/-}(\mathrm{n}=8)$ mice infected intraperitoneally with $10^{3} \mathrm{CFU}$ of $S$. Typhimurium.

(B) Survival of WT $(\mathrm{n}=13), I l 18^{-/-} I l 1 r^{-/-}(\mathrm{n}=4), \operatorname{Gsdmd}^{--}(\mathrm{n}=9), \operatorname{Caspl}^{-/-}(\mathrm{n}=7)$, and Irf8 mice infected as (A).

(C) Bacterial burden in tissues. For spleen, WT (n=10), $I l 18^{-/-} I l 1 r^{-/-}(\mathrm{n}=11), G s d m d^{--}$ $(\mathrm{n}=11), \operatorname{Casp1}^{-/-}(\mathrm{n}=8)$, and $\operatorname{Irf8}^{-/-}(\mathrm{n}=7)$ mice; for liver, WT $(\mathrm{n}=10), \operatorname{Ill}^{-/-} \operatorname{IlIr}^{-/-}(\mathrm{n}=12)$, $\operatorname{Gsdmd}^{--}(\mathrm{n}=11), \operatorname{Caspl}^{-/-}(\mathrm{n}=7)$, and $\operatorname{Irfg}^{-/-}(\mathrm{n}=7)$ mice on day 3 after infection as (A). NS, not significant; $* * \mathrm{P}<0.001$ and $* * * \mathrm{P}<0.0001$ (log-rank test [B] or ANOVA with Dunn's multiple comparisons test [C]). Data are from 1 experiment. 


\section{CHAPTER 4. DISCUSSION ${ }^{3,4}$}

\section{IRF8 and the Inflammasome}

In comparison to the well-studied NLRP3 inflammasome, how NLRC4 inflammasome activity is controlled has been unknown. Activation of the NLRC4 inflammasome is crucial for defense against pathogenic bacteria that harbor flagellin or the T3SS. Mice lacking NLRC4 or NAIPs have increased bacterial loads. The NLRC4 inflammasome promotes bacterial clearance by the expulsion of bacteria-containing intestinal epithelial cells from $S$. Typhimurium-challenged mice ${ }^{74,75}$. We discovered that IRF8 mediates NLRC4 inflammasome activation by transcriptionally regulating NAIPs, thereby enabling cellular detection of flagellin or T3SS proteins. In vivo, we found IRF8 is important for NLRC4 inflammasome-dependent cytokine production, bacterial clearance, and ultimately, host survival ${ }^{76,77}$. Previous studies have demonstrated that type IFNs and IRF1 contribute to bacteria-induced AIM2 and non-canonical NLRP3 inflammasome activation ${ }^{21-24,26}$. By introducing IRF8 as a novel player in inflammasome regulation, our findings also suggest a common cellular function for IRFs in promoting inflammasome activation during bacterial infection.

Although our study has convincingly demonstrated the role of IRF8 in transcriptional regulation of NAIPs, there are also other mechanisms by which IRF8 could modulate NLRC4 inflammasome activation. One study found that IRF8-dependent autophagy is important for the clearance of Listeria monocytogenes in macrophages ${ }^{78}$. As the relation between inflammasomes and autophagy is being increasingly explored, it would be interesting to know how NLRC4 inflammasome activation is affected by this fundamental cellular process. Also, phosphorylation of NLRC4 is required for inflammasome activation, and PKC $\delta$ is involved in this event ${ }^{79}$. Prkcd, the gene encoding PKC $\delta$, was upregulated after induced expression of IRF8 in a myeloid progenitor cell line ${ }^{80}$. This raises the question as to whether IRF8 could have additional roles upstream of NLRC4 inflammasome activation. In addition, apart from controlling inflammasome activation, IRF8 is known for promoting development of cDC1s and $\mathrm{pDCs}^{81}$, which might also have contributed to the increased susceptibility of $\operatorname{Irf} 8^{-/-}$mice to Salmonella and Burkholderia infections.

\footnotetext{
${ }^{3}$ Portions of chapter from previously published article; modified from final submission with permission. Karki R*, Lee E*, Place D, Samir P, Mavuluri J, Sharma BR, et al. IRF8 Regulates Transcription of Naips for NLRC4 Inflammasome Activation. Cell. 2018 May 3;173(4):920-933.e13. (*Co-first author). https://doi.org/10.1016/j.cell.2018.02.055 [76].

${ }^{4}$ Portions of chapter from previously published article; modified from final submission with open access permission. Lee E, Karki R, Kanneganti T-D. The NLRC4 inflammasome requires IRF8-dependent production of NAIPs. Cell Stress. 2018 May 22;2(6):144-6. https://doi.org/10.15698/cst2018.06.141 [77].
} 


\section{Additional Factors That May Regulate NLRC4 Inflammasome}

The residual expression of Naips and NLRC4 inflammasome activity in the absence of IRF8 imply that other factors may also contribute to the transcription of NAIPs. IRF8 is known to be recruited with other transcription factors owing to its weak DNA-binding activity. IRF, AP-1, and Ets family transcription factors interact with IRF8 to bind to specific composite elements allowing combinatorial control over numerous genes ${ }^{27,82,83}$. In our network analysis, IRF4 and SPI1 are co-expressed with IRF8. ChIPseq analysis indicates that SPI1 but not IRF4 binds to the promoter regions of Naips. Therefore, it is also possible that SPI1 could function with IRF8 to regulate gene expression of Naips and NLRC4 inflammasome activation. Whether IRF8 and SPI1 share common binding sites for Naips needs to be explored.

\section{Physiological Relevance of Differential Expression of Naips}

The basally lower expression of Naip genes in IRF8-deficient mice resulted in defective activation of the NLRC4 inflammasome. $\operatorname{Irf} 8^{-/-}$mice infected with $S$. Typhimurium or B. thailandensis had reduced gene expression of Naips in the spleen and lungs, which contain heterogeneous populations of cells. Macrophages are not the only cells to undergo NLRC4 inflammasome activation. NLRC4 inflammasome activation has been shown in monocytes, dendritic cells, neutrophils, and lymphocytes ${ }^{84-88}$. Thus, inflammasome activation from many different cell types may contribute to NLRC4 inflammasome-mediated protection against bacterial pathogens.

We showed that IRF8-dependent expression of individual Naip genes varies among tissues. The expression of Naip1, Naip5, Naip6, and Nlrc4, but not of Naip2, was basally lower in the spleens of $\operatorname{Irf} 8^{-/-}$mice than in those of WT mice. However, when we analyzed gene expression in the lungs, there was a significant reduction in Naip2 expression as well as the other Naips. In certain cell types, other transcriptional factors such as SPI1 may be more critical than IRF8. For instance, neutrophils do not express IRF8 but nevertheless express NAIP and are able to activate the NLRC4

inflammasome ${ }^{86,89}$. It will be important to assess how IRF8 and SPI1 expression relates to NAIP expression and NLRC4 inflammasome activation in different tissues and cell types. In addition, different bacterial species produce variable amounts of single or multiple NAIP ligands of varying affinity. The relative expression of Naips that would be able to detect those ligands would also differ among heterogenous cell types. This combination of host factors and pathogen factors may produce an astonishing degree of complexity in NLRC4 inflammasome activation in vivo.

It is interesting that transcription of Naips was dependent on IRF8, but there was no significant induction of Naips in vitro and in vivo in response to infection. We observed that IRF8 expression in the spleens of $S$. Typhimurium-infected mice was downregulated compared to that in the spleens of uninfected mice. This suggests that a negative-feedback mechanism may restrict overt inflammasome activation during persistent infection. Altogether, our work on IRF8 provides new insights into the 
regulation of the NAIP/NLRC4 inflammasome. The relationship among IRFs, the IFN signaling pathway, and inflammasomes remains to be further explored. 


\section{LIST OF REFERENCES}

1. Man SM, Kanneganti T-D. Regulation of inflammasome activation. Immunol Rev. 2015 May 1;265(1):6-21.

2. Kayagaki N, Stowe IB, Lee BL, O'Rourke K, Anderson K, Warming S, et al. Caspase-11 cleaves gasdermin D for non-canonical inflammasome signalling. Nature. 2015 Oct 29;526(7575):666-71.

3. Shi J, Zhao Y, Wang K, Shi X, Wang Y, Huang H, et al. Cleavage of GSDMD by inflammatory caspases determines pyroptotic cell death. Nature. 2015 Oct 29;526(7575):660-5.

4. Liu X, Zhang Z, Ruan J, Pan Y, Magupalli VG, Wu H, et al. Inflammasomeactivated gasdermin $\mathrm{D}$ causes pyroptosis by forming membrane pores. Nature. 2016 Jul;535(7610):153.

5. Poyet J-L, Srinivasula SM, Tnani M, Razmara M, Fernandes-Alnemri T, Alnemri ES. Identification of Ipaf, a Human Caspase-1-activating Protein Related to Apaf1. J Biol Chem. 2001 Jul 27;276(30):28309-13.

6. Franchi L, Amer A, Body-Malapel M, Kanneganti T-D, Ozören N, Jagirdar R, et al. Cytosolic flagellin requires Ipaf for activation of caspase-1 and interleukin 1 beta in salmonella-infected macrophages. Nat Immunol. 2006 Jun;7(6):576-82.

7. Miao EA, Alpuche-Aranda CM, Dors M, Clark AE, Bader MW, Miller SI, et al. Cytoplasmic flagellin activates caspase- 1 and secretion of interleukin $1 \beta$ via Ipaf. Nat Immunol. 2006 Jun;7(6):569-75.

8. Mariathasan S, Newton K, Monack DM, Vucic D, French DM, Lee WP, et al. Differential activation of the inflammasome by caspase-1 adaptors ASC and Ipaf. Nature. 2004 Jul 8;430(6996):213-8.

9. Broz P, Moltke J von, Jones JW, Vance RE, Monack DM. Differential Requirement for Caspase-1 Autoproteolysis in Pathogen-Induced Cell Death and Cytokine Processing. Cell Host \& Microbe. 2010 Dec 16;8(6):471-83.

10. Raupach B, Peuschel S-K, Monack DM, Zychlinsky A. Caspase-1-Mediated Activation of Interleukin-1 $\beta$ (IL-1 $\beta$ ) and IL-18 Contributes to Innate Immune Defenses against Salmonella enterica Serovar Typhimurium Infection. Infect Immun. 2006 Aug 1;74(8):4922-6.

11. Franchi L, Kamada N, Nakamura Y, Burberry A, Kuffa P, Suzuki S, et al. NLRC4-driven production of IL-1 $\beta$ discriminates between pathogenic and commensal bacteria and promotes host intestinal defense. Nat Immunol. 2012 May;13(5):449-56.

12. Zamboni DS, Kobayashi KS, Kohlsdorf T, Ogura Y, Long EM, Vance RE, et al. The Bircle cytosolic pattern-recognition receptor contributes to the detection and control of Legionella pneumophila infection. Nat Immunol. 2006 Mar;7(3):31825.

13. Zhao Y, Shao F. The NAIP-NLRC4 inflammasome in innate immune detection of bacterial flagellin and type III secretion apparatus. Immunol Rev. 2015 May 1;265(1):85-102.

14. Kofoed EM, Vance RE. Innate immune recognition of bacterial ligands by NAIPs determines inflammasome specificity. Nature. 2011 Sep 29;477(7366):592-5. 
15. Zhao Y, Yang J, Shi J, Gong Y-N, Lu Q, Xu H, et al. The NLRC4 inflammasome receptors for bacterial flagellin and type III secretion apparatus. Nature. 2011 Sep 29;477(7366):596-600.

16. Rauch I, Tenthorey JL, Nichols RD, Moussawi KA, Kang JJ, Kang C, et al. NAIP proteins are required for cytosolic detection of specific bacterial ligands in vivo. Journal of Experimental Medicine. 2016 May 2;213(5):657-65.

17. Zhao Y, Shi J, Shi X, Wang Y, Wang F, Shao F. Genetic functions of the NAIP family of inflammasome receptors for bacterial ligands in mice. Journal of Experimental Medicine. 2016 May 2;213(5):647-56.

18. Yang J, Zhao Y, Shi J, Shao F. Human NAIP and mouse NAIP1 recognize bacterial type III secretion needle protein for inflammasome activation. PNAS. 2013 Aug 27;110(35):14408-13.

19. Kortmann J, Brubaker SW, Monack DM. Cutting Edge: Inflammasome Activation in Primary Human Macrophages Is Dependent on Flagellin. The Journal of Immunology. 2015 Aug 1;195(3):815-9.

20. Grandjean T, Boucher A, Thepaut M, Monlezun L, Guery B, Faudry E, et al. The human NAIP-NLRC4-inflammasome senses the Pseudomonas aeruginosa T3SS inner-rod protein. Int Immunol. 2017 Aug 1;29(8):377-84.

21. Rathinam VAK, Vanaja SK, Waggoner L, Sokolovska A, Becker C, Stuart LM, et al. TRIF Licenses Caspase-11-Dependent NLRP3 Inflammasome Activation by Gram-Negative Bacteria. Cell. 2012 Aug 3;150(3):606-19.

22. Broz P, Ruby T, Belhocine K, Bouley DM, Kayagaki N, Dixit VM, et al. Caspase-11 increases susceptibility to Salmonella infection in the absence of caspase-1. Nature. 2012 Oct 11;490(7419):288-91.

23. Henry T, Brotcke A, Weiss DS, Thompson LJ, Monack DM. Type I interferon signaling is required for activation of the inflammasome during Francisella infection. Journal of Experimental Medicine. 2007 May 14;204(5):987-94.

24. Fernandes-Alnemri T, Yu J-W, Juliana C, Solorzano L, Kang S, Wu J, et al. The AIM2 inflammasome is critical for innate immunity to Francisella tularensis. Nat Immunol. 2010 May;11(5):385-93.

25. Tamura T, Yanai H, Savitsky D, Taniguchi T. The IRF family transcription factors in immunity and oncogenesis. Annu Rev Immunol. 2008;26:535-84.

26. Man SM, Karki R, Malireddi RKS, Neale G, Vogel P, Yamamoto M, et al. The transcription factor IRF1 and guanylate-binding proteins target activation of the AIM2 inflammasome by Francisella infection. Nat Immunol. 2015 May;16(5):467-75.

27. Bovolenta C, Driggers PH, Marks MS, Medin JA, Politis AD, Vogel SN, et al. Molecular interactions between interferon consensus sequence binding protein and members of the interferon regulatory factor family. Proc Natl Acad Sci U S A. 1994 May 24;91(11):5046-50.

28. Harada H, Fujita T, Miyamoto M, Kimura Y, Maruyama M, Furia A, et al. Structurally similar but functionally distinct factors, IRF-1 and IRF-2, bind to the same regulatory elements of IFN and IFN-inducible genes. Cell. 1989 Aug 25;58(4):729-39.

29. Driggers PH, Ennist DL, Gleason SL, Mak WH, Marks MS, Levi BZ, et al. An interferon gamma-regulated protein that binds the interferon-inducible enhancer 
element of major histocompatibility complex class I genes. PNAS. 1990 May 1;87(10):3743-7.

30. Barber SA, Fultz MJ, Salkowski CA, Vogel SN. Differential expression of interferon regulatory factor 1 (IRF-1), IRF-2, and interferon consensus sequence binding protein genes in lipopolysaccharide (LPS)-responsive and LPShyporesponsive macrophages. Infect Immun. 1995 Feb 1;63(2):601-8.

31. Lehtonen A, Matikainen S, Julkunen I. Interferons up-regulate STAT1, STAT2, and IRF family transcription factor gene expression in human peripheral blood mononuclear cells and macrophages. The Journal of Immunology. 1997 Jul 15;159(2):794-803.

32. Wang I-M, Contursi C, Masumi A, Ma X, Trinchieri G, Ozato K. An IFN- $\gamma$ Inducible Transcription Factor, IFN Consensus Sequence Binding Protein (ICSBP), Stimulates IL-12 p40 Expression in Macrophages. The Journal of Immunology. $2000 \mathrm{Jul}$ 1;165(1):271-9.

33. Masumi A, Tamaoki S, Wang I-M, Ozato K, Komuro K. IRF-8/ICSBP and IRF-1 cooperatively stimulate mouse IL-12 promoter activity in macrophages. FEBS Letters. 2002 Nov 6;531(2):348-53.

34. Xiong H, Zhu C, Li H, Chen F, Mayer L, Ozato K, et al. Complex Formation of the Interferon (IFN) Consensus Sequence-binding Protein with IRF-1 Is Essential for Murine Macrophage IFN- $\gamma$-induced iNOS Gene Expression. J Biol Chem. 2003 Jan 24;278(4):2271-7.

35. Liu J, Guan X, Tamura T, Ozato K, Ma X. Synergistic Activation of Interleukin12 p35 Gene Transcription by Interferon Regulatory Factor-1 and Interferon Consensus Sequence-binding Protein. J Biol Chem. 2004 Dec 31;279(53):5560917.

36. Langlais D, Barreiro LB, Gros $\mathrm{P}$. The macrophage IRF8/IRF1 regulome is required for protection against infections and is associated with chronic inflammation. Journal of Experimental Medicine. 2016 Apr 4;213(4):585-603.

37. Matsuyama T, Kimura T, Kitagawa M, Pfeffer K, Kawakami T, Watanabe N, et al. Targeted disruption of IRF-1 or IRF-2 results in abnormal type I IFN gene induction and aberrant lymphocyte development. Cell. 1993 Oct 8;75(1):83-97.

38. Kanneganti T-D, Ozören N, Body-Malapel M, Amer A, Park J-H, Franchi L, et al. Bacterial RNA and small antiviral compounds activate caspase-1 through cryopyrin/Nalp3. Nature. 2006 Mar 9;440(7081):233-6.

39. Jones JW, Kayagaki N, Broz P, Henry T, Newton K, O'Rourke K, et al. Absent in melanoma 2 is required for innate immune recognition of Francisella tularensis. PNAS. 2010 May 25;107(21):9771-6.

40. Gorp HV, Saavedra PHV, Vasconcelos NM de, Opdenbosch NV, Walle LV, Matusiak M, et al. Familial Mediterranean fever mutations lift the obligatory requirement for microtubules in Pyrin inflammasome activation. PNAS. 2016 Dec 13;113(50):14384-9.

41. Lightfield KL, Persson J, Brubaker SW, Witte CE, von Moltke J, Dunipace EA, et al. Critical function for Naip5 in inflammasome activation by a conserved carboxy-terminal domain of flagellin. Nat Immunol. 2008 Oct;9(10):1171-8. 
42. Man SM, Karki R, Briard B, Burton A, Gingras S, Pelletier S, et al. Differential roles of caspase-1 and caspase-11 in infection and inflammation. Sci Rep. 2017 27:7:45126.

43. Kayagaki N, Warming S, Lamkanfi M, Vande Walle L, Louie S, Dong J, et al. Non-canonical inflammasome activation targets caspase-11. Nature. 2011 Oct 16;479(7371):117-21.

44. Sato M, Suemori H, Hata N, Asagiri M, Ogasawara K, Nakao K, et al. Distinct and essential roles of transcription factors IRF-3 and IRF-7 in response to viruses for IFN-alpha/beta gene induction. Immunity. 2000 Oct;13(4):539-48.

45. Honda K, Yanai H, Negishi H, Asagiri M, Sato M, Mizutani T, et al. IRF-7 is the master regulator of type-I interferon-dependent immune responses. Nature. 2005 Apr 7;434(7034):772-7.

46. Kimura T, Kadokawa Y, Harada H, Matsumoto M, Sato M, Kashiwazaki Y, et al. Essential and non-redundant roles of p48 (ISGF3 gamma) and IRF-1 in both type I and type II interferon responses, as revealed by gene targeting studies. Genes Cells. 1996 Jan;1(1):115-24.

47. Müller U, Steinhoff U, Reis LF, Hemmi S, Pavlovic J, Zinkernagel RM, et al. Functional role of type I and type II interferons in antiviral defense. Science. 1994 Jun 24;264(5167):1918-21.

48. Fenner JE, Starr R, Cornish AL, Zhang J-G, Metcalf D, Schreiber RD, et al. Suppressor of cytokine signaling 1 regulates the immune response to infection by a unique inhibition of type I interferon activity. Nat Immunol. 2006 Jan;7(1):33-9.

49. Yamamoto M, Sato S, Hemmi H, Hoshino K, Kaisho T, Sanjo H, et al. Role of adaptor TRIF in the MyD88-independent toll-like receptor signaling pathway. Science. 2003 Aug 1;301(5633):640-3.

50. Suthar MS, Ramos HJ, Brassil MM, Netland J, Chappell CP, Blahnik G, et al. The RIG-I-like receptor LGP2 controls CD8(+) T cell survival and fitness. Immunity. 2012 Aug 24;37(2):235-48.

51. Kato H, Takeuchi O, Sato S, Yoneyama M, Yamamoto M, Matsui K, et al. Differential roles of MDA5 and RIG-I helicases in the recognition of RNA viruses. Nature. 2006 May 4;441(7089):101-5.

52. Schoggins JW, MacDuff DA, Imanaka N, Gainey MD, Shrestha B, Eitson JL, et al. Pan-viral specificity of IFN-induced genes reveals new roles for cGAS in innate immunity. Nature. 2014 Jan 30;505(7485):691-5.

53. Sauer J-D, Sotelo-Troha K, von Moltke J, Monroe KM, Rae CS, Brubaker SW, et al. The N-ethyl-N-nitrosourea-induced Goldenticket mouse mutant reveals an essential function of Sting in the in vivo interferon response to Listeria monocytogenes and cyclic dinucleotides. Infect Immun. 2011 Feb;79(2):688-94.

54. Kuehne SA, Collery MM, Kelly ML, Cartman ST, Cockayne A, Minton NP. Importance of toxin A, toxin B, and CDT in virulence of an epidemic Clostridium difficile strain. J Infect Dis. 2014 Jan 1;209(1):83-6.

55. Huang DW, Sherman BT, Lempicki RA. Systematic and integrative analysis of large gene lists using DAVID bioinformatics resources. Nat Protoc. 2009;4(1):44-57. 
56. Mostafavi S, Ray D, Warde-Farley D, Grouios C, Morris Q. GeneMANIA: a realtime multiple association network integration algorithm for predicting gene function. Genome Biol. 2008;9 Suppl 1:S4.

57. Olsson A, Venkatasubramanian M, Chaudhri VK, Aronow BJ, Salomonis N, Singh H, et al. Single-cell analysis of mixed-lineage states leading to a binary cell fate choice. Nature. 2016 29;537(7622):698-702.

58. Iwata A, Durai V, Tussiwand R, Briseño CG, Wu X, Grajales-Reyes GE, et al. Quality of TCR signaling determined by differential affinities of enhancers for the composite BATF-IRF4 transcription factor complex. Nat Immunol.

2017;18(5):563-72.

59. Robinson JT, Thorvaldsdóttir H, Winckler W, Guttman M, Lander ES, Getz G, et al. Integrative genomics viewer. Nat Biotechnol. 2011 Jan;29(1):24-6.

60. Jones CL, Napier BA, Sampson TR, Llewellyn AC, Schroeder MR, Weiss DS. Subversion of Host Recognition and Defense Systems by Francisella spp. Microbiol Mol Biol Rev. 2012 Jun 1;76(2):383-404.

61. Kurotaki D, Tamura T. Transcriptional and Epigenetic Regulation of Innate Immune Cell Development by the Transcription Factor, Interferon Regulatory Factor-8. Journal of Interferon \& Cytokine Research. 2016 Jul 1;36(7):433-41.

62. Xu H, Yang J, Gao W, Li L, Li P, Zhang L, et al. Innate immune sensing of bacterial modifications of Rho GTPases by the Pyrin inflammasome. Nature. 2014 Sep 11;513(7517):237-41.

63. Sutterwala FS, Mijares LA, Li L, Ogura Y, Kazmierczak BI, Flavell RA. Immune recognition of Pseudomonas aeruginosa mediated by the IPAF/NLRC4 inflammasome. Journal of Experimental Medicine. 2007 Dec 24;204(13):3235-45.

64. Amer A, Franchi L, Kanneganti T-D, Body-Malapel M, Özören N, Brady G, et al. Regulation of Legionella Phagosome Maturation and Infection through Flagellin and Host Ipaf. J Biol Chem. 2006 Nov 17;281(46):35217-23.

65. Crowley SM, Knodler LA, Vallance BA. Salmonella and the Inflammasome: Battle for Intracellular Dominance. Curr Top Microbiol Immunol. 2016;397:4367.

66. Fàbrega A, Vila J. Salmonella enterica Serovar Typhimurium Skills To Succeed in the Host: Virulence and Regulation. Clin Microbiol Rev. $2013 \mathrm{Apr}$ $1 ; 26(2): 308-41$.

67. Storek KM, Monack DM. Bacterial recognition pathways that lead to inflammasome activation. Immunol Rev. 2015 May 1;265(1):112-29.

68. Man SM, Hopkins LJ, Nugent E, Cox S, Glück IM, Tourlomousis P, et al. Inflammasome activation causes dual recruitment of NLRC4 and NLRP3 to the same macromolecular complex. PNAS. 2014 May 20;111(20):7403-8.

69. Jones JDG, Vance RE, Dangl JL. Intracellular innate immune surveillance devices in plants and animals. Science. 2016 Dec 2;354(6316):aaf6395.

70. Yamagata T, Nishida J, Tanaka S, Sakai R, Mitani K, Yoshida M, et al. A novel interferon regulatory factor family transcription factor, ICSAT/Pip/LSIRF, that negatively regulates the activity of interferon-regulated genes. Mol Cell Biol. 1996 Apr 1;16(4):1283-94. 
71. Martone R, Euskirchen G, Bertone P, Hartman S, Royce TE, Luscombe NM, et al. Distribution of NF-kappaB-binding sites across human chromosome 22. Proc Natl Acad Sci USA. 2003 Oct 14;100(21):12247-52.

72. Tokuhiro S, Yamada R, Chang X, Suzuki A, Kochi Y, Sawada T, et al. An intronic SNP in a RUNX1 binding site of SLC22A4, encoding an organic cation transporter, is associated with rheumatoid arthritis. Nat Genet. 2003 Dec;35(4):341-8.

73. Carvalho FA, Nalbantoglu I, Aitken JD, Uchiyama R, Su Y, Doho GH, et al. Cytosolic flagellin receptor NLRC4 protects mice against mucosal and systemic challenges. Mucosal Immunol. 2012 May;5(3):288-98.

74. Sellin ME, Müller AA, Felmy B, Dolowschiak T, Diard M, Tardivel A, et al. Epithelium-Intrinsic NAIP/NLRC4 Inflammasome Drives Infected Enterocyte Expulsion to Restrict Salmonella Replication in the Intestinal Mucosa. Cell Host \& Microbe. 2014 Aug 13;16(2):237-48.

75. Rauch I, Deets KA, Ji DX, Moltke J von, Tenthorey JL, Lee AY, et al. NAIPNLRC4 Inflammasomes Coordinate Intestinal Epithelial Cell Expulsion with Eicosanoid and IL-18 Release via Activation of Caspase-1 and -8. Immunity. 2017 Apr 11 [cited 2017 Apr 11];0(0). Available from: http://www.cell.com/immunity/abstract/S1074-7613(17)30126-7

76. Karki R, Lee E, Place D, Samir P, Mavuluri J, Sharma BR, et al. IRF8 Regulates Transcription of Naips for NLRC4 Inflammasome Activation. Cell. 2018 May 3;173(4):920-933.e13.

77. Lee E, Karki R, Kanneganti T-D. The NLRC4 inflammasome requires IRF8dependent production of NAIPs. Cell Stress. 2018 May 22;2(6):144-6.

78. Gupta M, Shin D-M, Ramakrishna L, Goussetis DJ, Platanias LC, Xiong H, et al. IRF8 directs stress-induced autophagy in macrophages and promotes clearance of Listeria monocytogenes. Nature Communications. 2015 Mar 16;6:6379.

79. Qu Y, Misaghi S, Izrael-Tomasevic A, Newton K, Gilmour LL, Lamkanfi M, et al. Phosphorylation of NLRC4 is critical for inflammasome activation. Nature. 2012 Oct 25;490(7421):539-42.

80. Tamura T, Thotakura P, Tanaka TS, Ko MSH, Ozato K. Identification of target genes and a unique cis element regulated by IRF-8 in developing macrophages. Blood. 2005 Sep 15;106(6):1938-47.

81. Sichien D, Scott CL, Martens L, Vanderkerken M, Van Gassen S, Plantinga M, et al. IRF8 Transcription Factor Controls Survival and Function of Terminally Differentiated Conventional and Plasmacytoid Dendritic Cells, Respectively. Immunity. 2016 Sep 20;45(3):626-40.

82. Eklund EA, Jalava A, Kakar R. PU.1, Interferon Regulatory Factor 1, and Interferon Consensus Sequence-binding Protein Cooperate to Increase gp91 phox Expression. J Biol Chem. 1998 May 29;273(22):13957-65.

83. Glasmacher E, Agrawal S, Chang AB, Murphy TL, Zeng W, Lugt BV, et al. A Genomic Regulatory Element That Directs Assembly and Function of ImmuneSpecific AP-1-IRF Complexes. Science. 2012 Nov 16;338(6109):975-80.

84. Abdelaziz DH, Gavrilin MA, Akhter A, Caution K, Kotrange S, Khweek AA, et al. Apoptosis-associated speck-like protein (ASC) controls Legionella 
pneumophila infection in human monocytes. J Biol Chem. 2011 Feb 4;286(5):3203-8.

85. Kupz A, Guarda G, Gebhardt T, Sander LE, Short KR, Diavatopoulos DA, et al. NLRC4 inflammasomes in dendritic cells regulate noncognate effector function by memory CD8+ T cells. Nat Immunol. 2012 Jan 8;13(2):162-9.

86. Chen KW, Groß CJ, Sotomayor FV, Stacey KJ, Tschopp J, Sweet MJ, et al. The Neutrophil NLRC4 Inflammasome Selectively Promotes IL-1 $\beta$ Maturation without Pyroptosis during Acute Salmonella Challenge. Cell Reports. 2014 Jul 24;8(2):570-82.

87. Perez-Lopez A, Rosales-Reyes R, Alpuche-Aranda CM, Ortiz-Navarrete V. Salmonella downregulates Nod-like receptor family CARD domain containing protein 4 expression to promote its survival in B cells by preventing inflammasome activation and cell death. J Immunol. 2013 Feb 1;190(3):1201-9.

88. Nichols RD, von Moltke J, Vance RE. NAIP/NLRC4 inflammasome activation in MRP8+ cells is sufficient to cause systemic inflammatory disease. Nat Commun. 2017 20;8(1):2209.

89. Yáñez A, Ng MY, Hassanzadeh-Kiabi N, Goodridge HS. IRF8 acts in lineagecommitted rather than oligopotent progenitors to control neutrophil vs monocyte production. Blood. 2015 Feb 26;125(9):1452-9. 


\section{VITA}

Ein Lee was born in the Republic of Korea in 1990. She graduated as a Medical Doctor in 2015 from Chungbuk National University (CBNU) College of Medicine, Republic of Korea. In 2016 she joined the Biomedical Sciences program in the College of Graduate Health Sciences (CGHS) of University of Tennessee Health Science Center (UTHSC) with a focus in Microbiology, Immunology, and Biochemistry. She is expected to receive her M.S. degree in 2019. 